\title{
Managing CSR Stakeholder Engagement: A New Conceptual Framework
}

\author{
Linda O'Riordan · Jenny Fairbrass
}

Received: 13 December 2012/ Accepted: 23 September 2013

(C) Springer Science+Business Media Dordrecht 2013

\begin{abstract}
As concepts of corporate social responsibility (CSR) continue to evolve, the predicament facing CSR managers when attempting to balance the differing interests of various stakeholders remains a persistent management challenge. A review of the extensive literature in this field reveals that the conceptualisation of corporate approaches to responsible stakeholder management remains underdeveloped. In particular, CSR practices within the specific context of the pharmaceutical industry, a sector which particularly dramatically depicts the stakeholder management dilemmas faced by business managers, has been under-researched. To address this gap, this paper utilises qualitative, exploratory data, obtained via multiple research methods, to investigate the CSR practices of major pharmaceutical companies in the UK and Germany. The data are employed to critically re-examine and revise a previously published explanatory framework which identifies the management steps involved in CSR stakeholder engagement. The resulting revised explanatory framework is the main contribution of this paper. By abstracting those factors which influence CSR practice, it provides an analytical tool which is designed to be of practical use for business decision-makers when managing their stakeholder engagement activities. Given that the research addresses values and ideals and prescribes practical recommendations for practitioners, it is essentially applied and
\end{abstract}

\footnotetext{
L. O'Riordan $(\bowtie)$

FOM Hochschule für Oekonomie \& Management, University of Applied Sciences, Leimkugelstraße 6, 45141 Essen, Germany

e-mail: linda.oriordan@t-online.de

J. Fairbrass

School of Management, University of Bradford, Emm Lane, Bradford BD9 4JL, UK

e-mail: j.fairbrass@bradford.ac.uk
}

normative in nature. Ultimately, the framework proposes a set of steps for developing CSR strategies which could help CSR professionals to make a 'mindset transition' from a narrower 'traditional' approach to CSR to a more innovative way of thinking.

Keywords CSR - Stakeholder management .

Stakeholder engagement · Conceptual frameworks . Pharmaceutical industry . UK and Germany

\section{Introduction}

Interest in the behaviour of firms, and particularly large companies, has been re-ignited in the past decade or so as a consequence of numerous reported 'scandals' involving firms such as banks, telecoms operators, energy companies and others (see for example Wagner 2006; May et al. 2007, p. 7; Peters and Roess 2010; Mallen 2012). In parallel with the critical public and media attention that these events have provoked, there has also been a burgeoning of the academic research into the topic of 'corporate social responsibility' (CSR, e.g. Carroll 1979; Lindgreen and Swaen 2010). Equally, there has also been a growth in practitioner concern for CSR and stakeholder management (see for example OECD 2001; WBCSD 2002; UN Global Compact 1999; International Business Leaders Forum [IBLF] 2010a; International Organization for Standardization [ISO] 2010, p. 4). These developments have triggered the very real challenge for business managers of deciding how, on a day-to-day practical basis, to operationalise CSR and manage their firm's obligations to their various stakeholders (O'Riordan and Fairbrass 2012a, b).

These issues are especially heightened for the industry selected as the focal point for the study reported in this paper: 
namely, the pharmaceutical industry. Arguably, the moral dilemmas surrounding CSR and its delivery are more acutely highlighted in this particularly 'sensitive' industry (e.g. Spinello 1992; Miles et al. 2002; Fischer 2009) as managers struggle to weigh up the competing considerations of their stakeholders' interests such as product pricing and product distribution, the ethics of animal testing, the making of (excessive) profits and the need to invest large sums to develop medication that can effectively combat serious, life-threatening disease (O'Riordan 2010, pp. 44-49). This paper concentrates on the pharmaceutical industry, partly because it is such an important 'test case' of CSR and stakeholder management given the nature and profile of the industry (e.g. Rifkin 2005; Ethical Corp. 2009), but also because, despite some preceding relevant exceptions (e.g. Doh and Guay 2006; Silberhorn and Warren 2007; Esteban 2008; Maon et al. 2008), research specifically relating to stakeholder management and its conceptualisation is generally lacking for this sector (e.g. Hoffmann and Fieseler 2010; O'Riordan 2010).

The point of departure for the current paper was an extensive literature review that led, in turn, to the development of an initial conceptual framework (which was published in this journal by the authors of this paper; see O'Riordan and Fairbrass 2008). While this first conceptual framework was designed to be of practical value to business managers by assisting them in their day-to-day CSR and stakeholder management activities, its validity was limited by the fact that it had been developed exclusively from desk research. To redress that shortcoming, extensive primary research has been undertaken in order to test, refine and thereby improve the original conceptualisation.

The primary research, which was completed between 2005 and 2010, employed a range of research methods including the documentary analysis of 38 company websites and reports, a telephone survey of 46 companies, observation of the CSR stakeholder management practices of 142 firms, and in-depth interviews with senior managers from the pharmaceutical industry. The underpinning objective for the research undertaken was to identify those key elements which may be particularly salient to business managers in the pharmaceutical industry in relation to their CSR stakeholder management activities. The investigation produced a substantial and detailed corpus of fresh empirical data which reveals significant insights into the views and behaviour of practising business managers in the pharmaceutical industry. The outcome of this data-gathering process is a new conceptual framework which more accurately reflects the key determinants of CSR stakeholder engagement for CSR managers in the pharmaceutical industry than the first conceptual framework proposal from 2008 (O'Riordan and Fairbrass 2008). The main purpose of this paper is to trace the development of that new conceptual framework. The substantial new and original data collected which enabled the resultant analytical tool builds on the 2008 framework's utility by producing an updated prescriptive instrument which is designed to guide decision-makers when forming and developing CSR stakeholder management strategies and policies. Consequently, together, the data and the framework offer an original and important contribution to both the academic and practitioner debates in the under-researched field of CSR stakeholder management (Lindgreen and Swaen 2010) particularly with respect to pharmaceutical sector (O'Riordan 2010).

The remainder of this paper unfolds as follows. The first section presents a short summary of the relevant academic literature which underpins this paper. Next, the first desk research-based conceptualisation of CSR stakeholder engagement practice is outlined. Then the methodology employed for the empirical research is briefly explained. The paper then proceeds to present the results ${ }^{1}$ of the study, which form the basis for a new and original conceptualisation of CSR and stakeholder management. The two conceptual frameworks are then compared in order to highlight the improvements that result from the extensive empirical research undertaken. The paper concludes by summarising the overall contribution of this paper, addressing the limitations of the work and suggesting recommendations for future research.

\section{Underpinning Concepts}

A review of the literature reveals insufficient research regarding the specific CSR stakeholder management and engagement perceptions and practices of decision-makers in the pharmaceutical industry (O'Riordan and Fairbrass 2012a, b). Before highlighting that deficiency, the next sections first introduce the concepts of stakeholder management and stakeholder engagement, respectively, in greater detail.

\section{Stakeholder Management}

From a micro-perspective of the firm, the concepts proposed in stakeholder theory (Freeman 1984; Phillips et al. 2003) and stakeholder capitalism (Freeman et al. 2007) suggest that investing time and other resources in addressing stakeholders' interests is a rational managerial activity. In contrast with the former profit-orientated (shareholder value) focus held by businesses in the past (e.g. Friedman

\footnotetext{
${ }_{1}^{1}$ Please note that the conceptual framework presented in this paper was refigured based on evidence which was obtained in separate research (O'Riordan 2010). If required, that research is available upon specific request.
} 
1970; Jensen and Meckling 1976), the more contemporary acceptance of the broader contribution of a stakeholder imparts a moral duty upon the organisation towards that stakeholder (e.g. Greenwood 2007, p. 321; Greenwood and van Buren 2010). This has triggered novel and on-going developments in management thinking and practice (see for example Ferrell et al. 2010). In this new approach, the social nature of value creation is more explicitly acknowledged as it advocates focusing management attention on 'the best that can be created together rather than avoiding the worst' (Freeman et al. 2007, p. 313).

However, for individual business managers who are searching for a clear working definition of stakeholder management, the fundamental dilemma of stakeholder theory is how to prioritise the myriad and diverse stakeholder claims from the broad range of actors involved. The main challenge for businesses is the task of concretely identifying to whom they are responsible, and how far that obligation extends (Mitchell et al. 1997, pp. 856-863; Greenwood 2007; O’Riordan and Fairbrass 2008, pp. 747-748; 2012a; O’Riordan 2010).

Rather than simply acting as agents of shareholders, the modern view of stakeholder democracy, corporate accountability, and governance means that managers are required to take into account the (frequently competing) rights and interests of all legitimate stakeholders. Essentially they face the task of balancing the competing interests of many stakeholders for the long-term survival of the firm (O'Riordan 2010, p. 37). In this regard, the problems of identifying and prioritising stakeholders and their claims, originally noted by Mitchell et al. (1997, p. 853), are more pertinent than ever today.

Consequently, attempting to manage the challenges identified with respect to the relationship between a business and its broad responsibility to multiple stakeholders in society assigns a new role to management as indicated immediately above. Significantly, the complexities of narrowly endeavouring to measure the relationship between a business and its stakeholders in society from a financial accounting perspective (see for example Greenfield 2004) provide a strong indication of the practical dilemmas associated with stakeholder management which decision-makers face. More generally, however, managing business relationships via company policies, practices and programmes, such as stakeholder prioritisation and other choices (i.e. Hill and Jones 2007, pp. 374-377), involves decisions about how to engage with a range of stakeholders. It is to this topic of stakeholder engagement that the next section now turns.

\section{CSR Stakeholder Engagement}

Stakeholder engagement can be defined as those practices which an organisation undertakes to involve stakeholders in a positive manner in organisational activities (Greenwood 2007, p. 317). It can comprise the process of establishing, developing and maintaining stakeholder relations. This can include stakeholder identification, consultation, communication, dialogue and exchange (Burchell and Cook 2006; Greenwood 2007, p. 322). More recently in this regard, the ISO 26000 principles for social responsibility define stakeholder engagement as all those activities which are undertaken to

create opportunities for dialogue between an organisation and one or more of its stakeholders with the aim of providing an informed basis for the organisation's decisions (ISO 2010:4).

Stakeholder engagement activities may accordingly exist within a broad range of business activities. In short,

The impetus behind the use of the term 'engagement' in the stakeholder theory and corporate social responsibility (CSR) literatures is the need to emphasize that, for firms merely to interact with stakeholders is no longer sufficient, if, in fact, it ever was. Interaction with stakeholders is a logically necessary activity of business (Noland and Phillips 2010).

Within this context, engagement can be seen as a mechanism to achieve a number of objectives including consent, control, co-operation, accountability and involvement, as a method for enhancing trust or as a substitute for true trust, as a discourse to enhance fairness or as a mechanism of corporate governance (Greenwood 2007, p. 318).

In ideal terms, stakeholder engagement could be interpreted as a mutually beneficial and just scheme of cooperation which takes the form of a 'moral partnership of equals' (Phillips 1997, p. 54). In this regard, an assortment of economic and behavioural exchange theories provide various additional insights for examining the independencies in these relationships (see for example Donaldson and O'Toole 2007, pp. 21-36). However, in reviewing the various possible depictions of stakeholder engagement from various theoretical traditions such as business ethics, social accounting and reporting, as well as human resource management, Greenwood (2007, p. 318) argues that stakeholder engagement is for the most part morally neutral. As a result, it can be employed in a moral or an immoral way. In business practice, it is the virtue of the actor which ultimately determines the motive behind the engagement undertaken. As a result, engagement with stakeholders does not necessarily equate with responsible business behaviour (Greenwood 2007, p. 320). Accordingly, the argument that stakeholder engagement is linked with responsible treatment of stakeholders is simplistic 
(Greenwood 2007, p. 325). Significantly in this regard, past scholarship reveals competing ideas about the proper motivation, method and manner of engaging stakeholders which has culminated in the emergence of a greater awareness of the need to reconceive the purpose of business and the nature of the firm. The most prominent recent trend in this respect is proposed by those scholars who take an Ethical Strategist view. Their interpretation provides the theoretical basis for including honest, open and respectful engagement of stakeholders as a vital part a firm's strategy (Noland and Phillips 2010).

They do this by calling our attention to the stakeholders who constitute the firm as people with 'names and faces' and reminding us of business's role in society's pursuit of the good life (Noland and Phillips 2010).

Crucially, the cognitive transition inherent in this inclusive approach empowers the very purpose of the firm and the capitalist system within which it operates to most optimally invest its resources to enable the creation of synergic value for all stakeholders as originally suggested by Freeman (e.g. Freeman 1984; Freeman et al. 2007).

More specifically in this regard, this evolution towards a greater focus upon stakeholders has resulted in the development of a broad range of engagement strategies which stretch from increased dissemination of information through detailed reporting practices towards more interactive stakeholder relationships (Burchell and Cook 2008, p. 35). Within the construct of stakeholder engagement, while rigid identification of the exact persons who qualify as stakeholders may be displaced, identification of what counts as a stakeholder claim is vital (Mitchell et al. 1997). Once this identification has taken place, increased emphasis is placed upon the concept of stakeholder communication and dialogue and its many formats (Burchell and Cook 2006; ISO 2010, pp. 73-76; O'Riordan 2010, pp. 39-40).

Significantly, CSR stakeholder engagement (including communication and other forms of dialogue) determines how the firm's CSR response is viewed and evaluated by stakeholders (O'Riordan and Fairbrass 2006). Accordingly, it is deemed to play a vital part in the development of CSR strategies (O'Riordan and Fairbrass 2008).

However, the broad and diverse nature of the term 'stakeholder', including its inherent range of actors, as well as the varying interpretations of CEOs depending on their perceptions regarding values performance (see for example Agle et al. 1999; Maak 2007), intrinsically pose a challenge in the search for a clear working definition for CSR for this target group (e.g. O'Riordan 2006). As a result, the task of managing effective CSR stakeholder engagement for individual business managers in general, but in particular in the pharmaceutical business, an industry, as described above, that is often termed 'sensitive', can be considered a demanding challenge (O'Riordan 2010, p. 44). The next section presents one potential solution for managing stakeholder engagement activities which aims to address this challenge.

\section{Conceptualising CSR Management}

The need for concept building in this field became evident during an extensive review of the previous academic literature which revealed a significant lack of theory and empirical data relating to stakeholder management and stakeholder engagement in the pharmaceutical industry. To elaborate, despite the pervasiveness of the issues described immediately above, an extensive literature review of the field reveals that whilst the general academic literature on topics which are directly related to CSR management (e.g. Ferrell et al. 2010) such as the relationship between business and society (e.g. Donaldson and O'Toole 2007, pp. 21-36; Schwartz and Carroll 2008; Albareda et al. 2008, p. 349; Carroll and Buchholtz 2009), business ethics (Crane and Matten 2010), stakeholder theory (Freeman 1984), stakeholder engagement (see for example Mitchell et al. 1997; Greenwood 2007; Burchell and Cook 2006, 2008; ISO 2010; Peters and Roess 2010, p. 8; IBLF 2010b; CSR Europe 2012; CSR Asia 2012), CSR (Carroll 1979), corporate citizenship (e.g. Maignan and Ferrell 2000), sustainability (e.g. Lozano 2010) and the triple bottom line (Elkington 1999) and more specifically pharmaceuticalrelated research (such stakeholder-integrated approach to healthcare management e.g. Zinkhan and Balazsb 2004) is vast and continually increasing, past scholarship which precisely explains how to manage CSR stakeholder engagement in practice and which exposes the factors which influence these practices is rather limited or deficient (Ferrell et al. 2010; Crane and Matten 2010, p. 224). Arguably, the very abundance of the literature on this broad range of related topics may actually compound the uncertainty and confusion among pharmaceutical business decision-makers (e.g. Crane and Matten 2010, p. 224; O'Riordan 2010) and lead to a lack of clarity and precision amongst scholars who actively research and theorise in this area of business activity.

Most significantly, a review of previous scholarship revealed some key studies which examine important research in CSR literature and identify critical research gaps (Carroll 1999; Garriga and Melé 2004; Lee 2008; Secchi 2007). In short, this suggests that the management of stakeholder engagement, as well as its influencing factors, have been under-researched (O'Riordan 2006, 2010; O'Riordan and Fairbrass 2008; Lindgreen et al. 2009). In this regard, recent literature (Lindgreen and Swaen 2010) 
maintains that conceptualisations of and research on CSR have evolved from a discussion of the macro-social effects to an organisational-level analysis of CSR and its impact on organisational processes and performance (Lee 2008). Whilst the extant literature includes some valuable contributions on the latter aspects (e.g. Porter and Kramer 2006), the active and applied aspects of developing a CSR orientation within organisational systems have emerged only recently in the literature (Jonker and De Witte 2006) and in practice (O'Riordan 2010). This development is acutely relevant because the literature suggests that in terms of the theoretical orientation of this field, researchers have now shifted from explicitly normative and ethicsoriented arguments to implicitly normative and performance-oriented managerial studies (Lindgreen and Swaen 2010). Significantly, however, despite the resulting urgent need for new practical tools for developing, implementing and measuring the results of a CSR orientation within an organisation, past scholarship highlights that many of the available management instruments are isolated or fragmented and, taken together, do not amount to a comprehensive or coherent overview of CSR and stakeholder management (Murray and Voge 1997, p. 141; Welford 2008; O'Riordan and Fairbrass 2008; Ferrell et al. 2010; Crane and Matten 2010, p. 224). Crucially in this regard, several leading authors expressly underline the lack of suitable frameworks or analytical tools with which to systematically analyse the management of CSR and stakeholder engagement (see for example Gray et al. 1995; Crane and Matten 2007, p. 516; Lindgreen and Swaen 2010; Ferrell et al. 2010). In short, the conceptual frameworks which are presented in this paper aim to make some contribution towards remedying these past deficiencies (O'Riordan 2010).

Consequently, these gaps triggered the search for a more specific yet comprehensive contribution which could distinguish the essential elements and steps involved in managing CSR. A systematic and extensive literature review initially identified that a number of important themes emerge as being particularly pertinent (O'Riordan 2006, 2010, p. 78; O'Riordan and Fairbrass 2008, p. 365). These themes include: 'CSR Drivers/Influencers'; 'Management Responses'; and 'Outcomes'. Essentially, these themes which are drawn from the secondary literature review formed the foundations that shaped the original framework. More specifically, in order to develop an explanatory conceptualisation, each of these main categories were further disaggregated, based on inferences from past scholarship which suggested that these elements might reflect the key determinants which require decisionmaker's attention when managing their CSR stakeholder engagement activities. For example, the 'CSR drivers/ influencers' category was sub-divided into three elements: the 'environmental context'; 'given circumstance'; 'people' and 'event'. The 'management response' category was interpreted to include aspects such as 'values', 'response alternatives' or 'options'; selection of 'response strategy', the 'CSR communication process' and 'stakeholder engagement/dialogue' as well as 'public relations', and 'control indicators'. Finally, an 'outcomes' category was developed to cover issues such as 'credibility', 'corporate identity' and 'social impact' (O'Riordan 2006, 2010, pp. $78-81$ ).

Having summarised the key findings in relation to the academic literature review, and briefly explained how the categories and elements which were identified from previous scholarship critically helped to inform the thinking which eventually resulted in the creation of the original framework proposal presented immediately below, the next section now turns to present that preliminary explanatory framework which was developed in response to the gaps identified in the extant literature.

\section{Desk-Based Research and the First Conceptual Framework}

In light of the weaknesses highlighted in the past scholarship above, an explanatory conceptual framework was developed by one of the authors in previous research (O'Riordan 2006, 2010; O'Riordan and Fairbrass 2008). The objective was to design a framework which would represent the core influencing factors involved in the management process as well as the main strategic management steps undertaken by business managers and which could be employed to examine the CSR practices found within the pharmaceutical industry. Figure 1 sets out the conceptual framework diagrammatically.

This conceptualisation identifies a series of four connected domains. These depict both the operating landscape and the determinants of stakeholder power (e.g. Pfeffer and Salancik 1978; Porter 1985; Fraser and Zarkada-Fraser 2003) which require consideration when devising CSR strategy and stakeholder engagement activities. The contention in constructing a structured, systematic, and comprehensive approach to CSR stakeholder engagement is that these four domains require particular consideration. The specific elements of this explanatory framework were selected for their merit in achieving a broad-ranging coverage of the issues which CSR decision-makers may encounter when attempting to manage their CSR stakeholder engagement activities (see O'Riordan 2010, pp. 53-96). In essence, this original framework was designed to set the scene for the entire CSR management process (O'Riordan 2006, 2010; O'Riordan and Fairbrass 2008). 
Fig. 1 Initial desk-based research framework

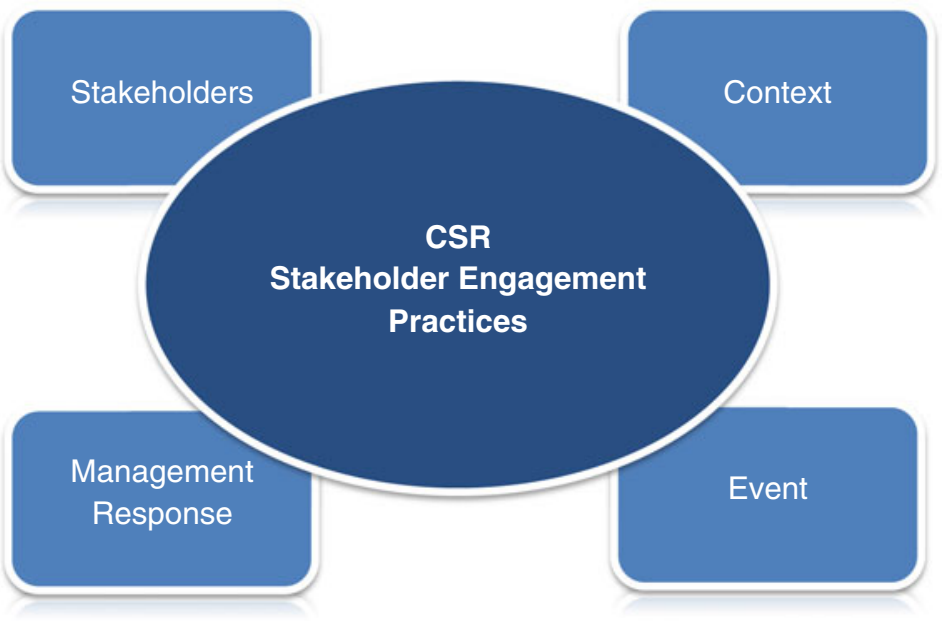

Management Response:

Phases \& Steps of the CSR Process:

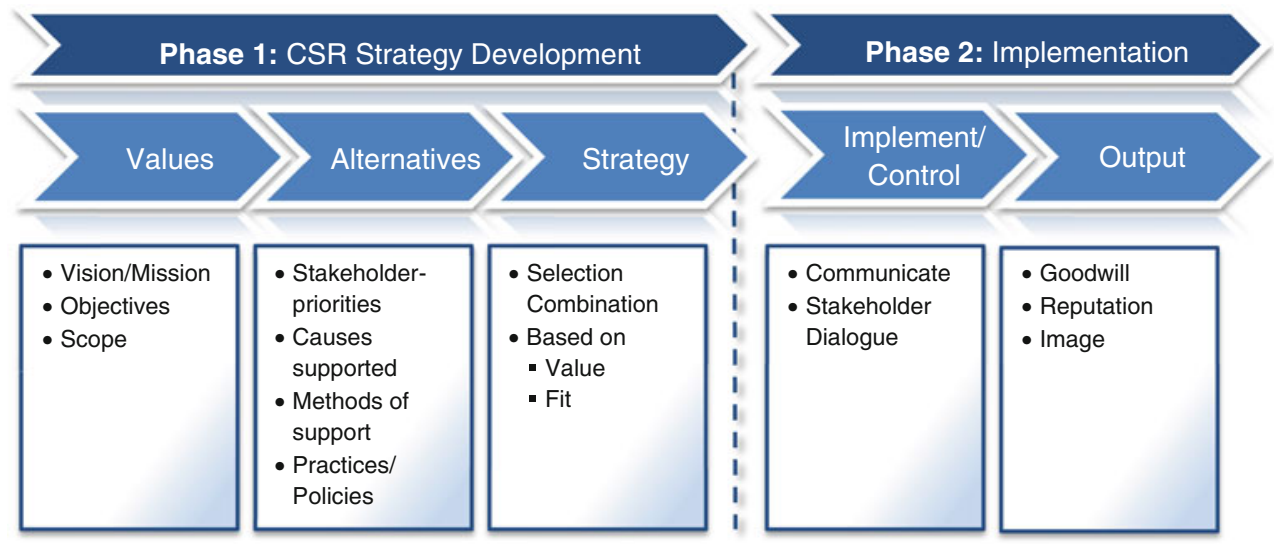

To develop these points, each of the four components is now examined in further detail. The first element, labelled 'context', addresses the external environment in which firms and their stakeholders operate. The second element focuses on the nature of 'stakeholders' themselves and their various (potentially conflicting) interests. This highlights the management process of the identification of stakeholders and their expectations (Mitchell et al. 1997; Frooman 1999; Matten and Moon 2008). The third element addresses the significance of a particular 'event' such as a serious health issue in a poverty-stricken region. This suggests that regardless of the favourable or unfavourable contexts and the particular actors involved, a specific event could trigger CSR issues. The fourth element concentrates on the potential or actual 'management response' within the operating context of the other factors or determinants. Since this framework is designed to be of practical use in CSR management, this element is more explicitly depicted as a two-phase process comprising the five strategic management steps which include 'values', 'alternatives', 'strategy', 'implement/control' and 'output'. Clearly, these components are not mutually exclusive. Rather, they interdependently and cumulatively relate to one another.

In summary, by depicting the key elements which require attention when managing their CSR stakeholder engagement activities, the original framework is useful because it builds on the previously available literature as discussed in the previous section (O'Riordan 2006; O'Riordan and Fairbrass 2008). More importantly, the original conceptualisation attempted to specifically address many of the concerns with respect to the management of stakeholder engagement which were identified in past scholarship. However, despite these two clear strengths, this framework was itself limited because it was based exclusively on desk research. Accordingly, the conceptualisation required empirical testing. Subsequently, research was conducted to gather detailed evidence about the practices, processes and relationships in CSR stakeholder 
management for the target group (O'Riordan 2010). The next section now addresses the research methodology which was employed during the data collection phase of that work.

\section{Methodology}

The knowledge gaps detected above highlight the need to examine more precisely how decision-makers in the pharmaceutical sector in the UK and Germany manage their day-to-day CSR stakeholder engagement activities, to establish what perceptions and other factors influence these practices (O'Riordan 2010, p. 7). To remedy the identified deficiencies, the empirical research undertaken that underpins this paper entailed a primarily qualitative study of senior business executives in major pharmaceutical companies in the UK and Germany (O'Riordan 2010). More specifically, a comparative case-study approach which used mixed methodologies was employed. The data were collected between 2005 and 2010 via documentary analysis of 38 company websites and reports, a telephone survey which generated 46 completed questionnaires, observation of the CSR stakeholder engagement practices of 142 pharmaceutical companies, and 18 in-depth interviews. A key part of the data analysis was the identification of six codes which were developed to aid the data management and presentation. Specifically, a review of past scholarship identified that the following codes could be particularly salient in CSR stakeholder management practice: 'terminology', 'stakeholders', 'communication/dialogue', 'organisation/governance', 'projects/activities' and 'expectations'. The findings from the four data collection sources were analysed and presented using content analysis based on these coding criteria categories which were derived exclusively from the literature review.

A major strength of this research design is the use of different methods which allow the capture of diverse evidence. Such triangulation assists in establishing rich data with greater trustworthiness (Robson 2004). The robust data obtained concerning the opinions and behaviour of the business managers help to identify CSR stakeholder engagement practices and to explain the factors which influence them. Crucially, the resulting findings provide the basis from which to explore, examine, update, test and thereby improve the original conceptual framework (see Fig. 1) which was limited because it was built exclusively from secondary data as one of the preliminary phases in separate research (O'Riordan 2006; O'Riordan and Fairbrass 2008). In this regard, a key aim of the empirical research was to collect data to more clearly establish three specific points with respect to that original conceptualisation. First, its value amongst the business managers in every-day CSR management. Second, the relevance and accuracy of the original framework's components (i.e. whether the four elements and their sub-elements in this framework precisely describe and explain CSR practice as well as the nature of their potential relationships), and third, how the original framework could be improved (O'Riordan 2010, pp. 380-383). The findings from this empirical research ultimately furnish the data with from which the new explanatory framework is enhanced. Significantly, this is the main contribution of this paper.

\section{Findings}

\section{Overview Summary of the Research Findings}

The findings from separate empirical research conducted over a 6-year period via various mixed methods (O'Riordan 2010) not only help to describe and explain CSR practice, but also assist in re-appraising the merits of the original framework (O'Riordan 2006; O'Riordan and Fairbrass 2008). This section briefly summarises those findings first with respect to the six evaluation codes, and then examines the value and accuracy of the original framework in CSR stakeholder management which, as a result of the evidence collected, now demands considerable alteration in both its appearance and substance.

First, the findings reveal that the CSR concepts and the resulting CSR stakeholder engagement practices adopted by the selected sample with respect to the six evaluation codes 'terminology', 'stakeholders', 'communication/dialogue', 'organisation/governance', 'projects/activities' and 'expectations' are diverse, interactive and dynamic. The data suggest that CSR business practice is potentially determined by a range of internal and external contextual factors. The evidence also indicates that CSR stakeholder engagement responses are still evolving as their interest groups' expectations continue to alter. ${ }^{2}$ Precisely how the explicit evidence from these coding categories resonates in the new revised framework is described in greater detail in the next section below. Overall, these findings point to three crucial factors in stakeholder management for business managers working in the pharmaceutical industry in the UK and Germany. First, the business managers perceive that stakeholders have negative perceptions of the pharmaceutical industry. Second, the evidence suggests that there may be misalignment between stated company values (mind-set) and actual CSR practices/policies within

\footnotetext{
${ }^{2}$ Please note that more detailed findings with respect to this research can be found if required in a separate paper by O'Riordan and Fairbrass (2012) entitled 'Corporate Approaches to CSR Stakeholder Engagement in the Pharmaceutical Industry'.
} 
the management process. Third, and most importantly, the findings reveal a major amount of management uncertainty due to operational complexity and stakeholder stance/ reaction. Significantly, this leads to a general lack of clarity about how to most effectively manage CSR, particularly in terms of how to scope and define CSR, how to measure the costs and benefits of CSR, and (consequently) how exactly to manage the CSR process (O'Riordan 2010). In summary, this research contributes by crucially furnishing a considerable amount of missing evidence with respect to how decision-makers in the pharmaceutical sector in the UK and Germany manage their day-to-day CSR stakeholder engagement activities and in establishing what perceptions and other factors influence these practices.

Second, the findings confirmed the original framework's relevance and practical helpfulness to decision-makers when managing CSR stakeholder engagement in daily practice. Given the significant uncertainty and complexity (mentioned immediately above) surrounding CSR practice, the interviewees in general confirm the overall practical usefulness of conceptualising the process steps in CSR stakeholder management in one comprehensive tool (O'Riordan 2010, p. 341). In particular, respondents stressed the framework's value as an instrument which maps CSR management processes when developing integrative management activities (e.g. Company 7 2008; Company 10 2008). Specifically, one senior CSR manager deemed the original conceptualisation to be useful because it 'helps to define a work flow and to clarify the steps that are needed to generate value' (Company 8 2008; O'Riordan 2010, p. 342). Additionally, the relevance and accuracy of the original framework's components in describing and explaining CSR practice as well as the nature of the inherent and potential relationships are positively evaluated (e.g. Company 1 2008; Company 5 2008; Company 11 2008; Company 14 2008). Importantly, by revealing the significance of values within the CSR management process as '...the basis for everything...' (e.g. Company 4 2008; Company 8 2008; Company 13 2008), the findings highlight and substantiate similar claims in previous scholarship (e.g. Fürst and Wieland 2004). Further praise for the original conceptualisation is offered by one very senior manager responsible for CSR at his company's European headquarters. He suggests that the framework 'has the advantage of being relatively simple'... but at the same time... 'not too abstract' (Company 4 2008). Overall, in the words of one senior CSR manager 'frameworks ....are always like a sparing partner' which allow us to 'check that we have thought about all the steps' (Company 8 2008).

While the data from the in-depth interviews furnish evidence which justify the practical need and usefulness of the original framework per se, many respondents also suggested the requirement to improve and extend the conceptualisation from its original form. Such evidence which was collected from both narrative and constructive criticism included advice regarding the additional need to consider aspects of CSR practice with respect to how to define managerial conceptualisations of CSR in differing operational contexts (e.g. Company 10 2008; Company 12 2008), as well as the relevance of a company's evolutionary stage of CSR development as an important influencing factor in CSR practice (e.g. Company 4 2008; Company 10 2008; Company 14 2008; Company 16 2008). This advice, as well as other comments with respect to suggestions to re-label, re-arrange and re-clarify some of the existing framework elements to better facilitate more practical (project-specific) implementation, triggered the requirement to alter the original 'communication', 'event' and 'management response' elements (O'Riordan 2010, pp. 348-349), as well as to develop the original framework version to more clearly signify the inter-relational linkages of its components (Company 3 2008; Company 15 2008).

The data which were collected and briefly summarised above help to describe and explain the key determinants in CSR stakeholder engagement practice. In short, the fresh empirical evidence reveals three specific results which drive the need to alter some of the elements and improve the level of detail of the original framework. These results include the uncertainty identified regarding how to most optimally communicate and organise CSR practice, calls for improved sustainability in the current CSR approach (i.e. practices which are better aligned to overall principles at operational level), and the evidence which suggests that the target group could manage their response more effectively (for instance to better leverage their CSR stakeholder engagement as a differentiating factor). Importantly, this evidence assists in re-appraising the merits of the original framework (O'Riordan 2006; O'Riordan and Fairbrass 2008) which, as a result, demands considerable alteration both in appearance and substance. Crucially, the findings expose not only why the original framework requires revision but also, more importantly, specifically how it can be improved (O'Riordan 2010, pp. 341-350). The next section now presents the revised analytical framework.

\section{The Revised Conceptual Framework}

By examining the stated opinions of senior pharmaceutical managers in the UK and Germany (O'Riordan 2010), the paper contributes to the literature on corporate approaches to CSR stakeholder engagement in the pharmaceutical industry in both countries. In doing so, it addresses many of the knowledge gaps, management challenges and the issues revealed in empirical evidence which were identified earlier in this paper. The amended version is shown in Fig. 2. 


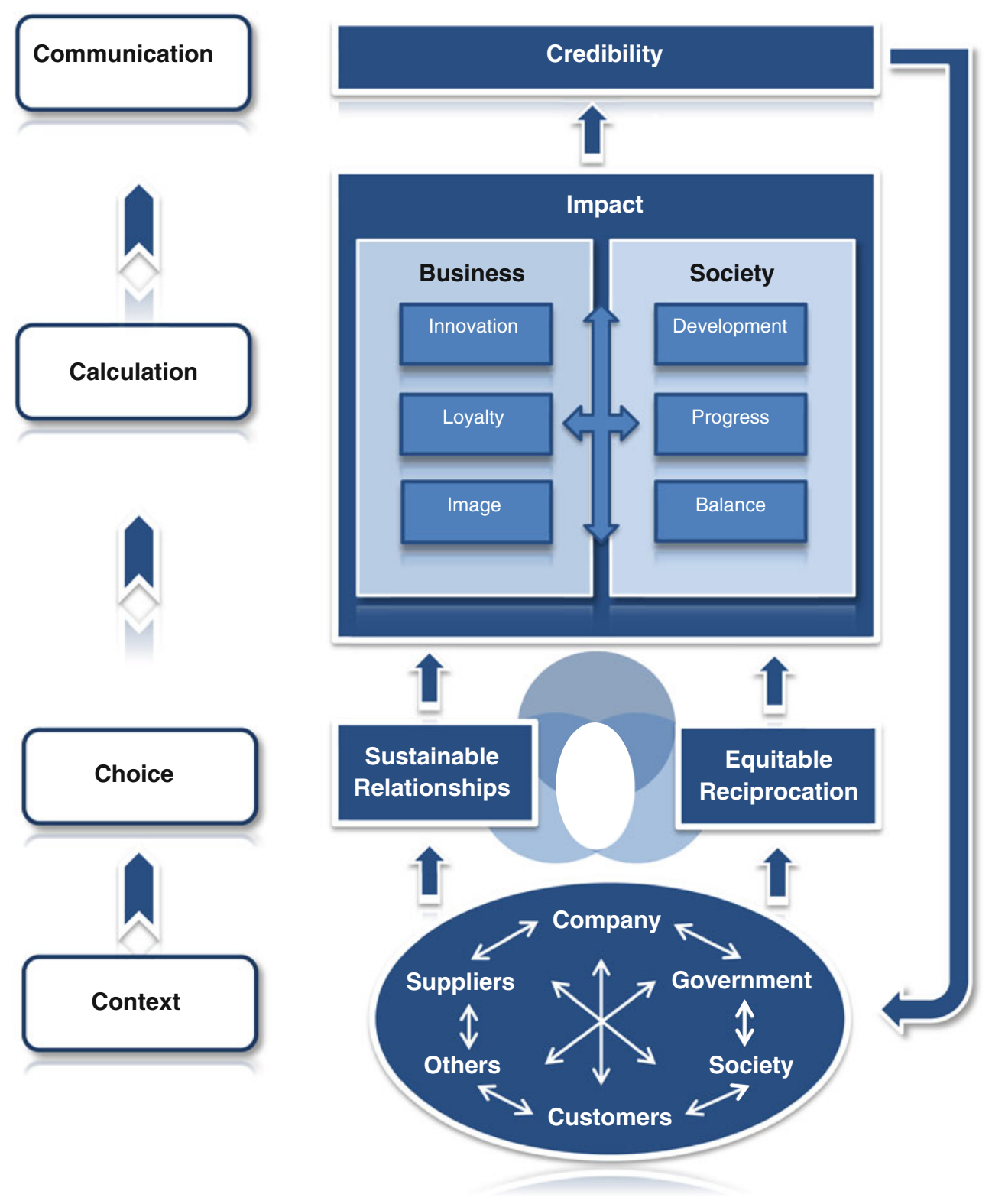

Fig. 2 Revised and refined framework

The new explanatory framework comprises a series of the four inter-related, interactive and synergic elements which are designed to more fully depict how decisionmakers in the pharmaceutical industry in the UK and Germany manage their CSR stakeholder engagement activities.

\section{The Components}

Given that this paper is seeking to provide practical and specific guidance to CSR managers in the pharmaceutical industry, this section now explains the key concepts of the components presented in Fig. 2 above in turn in greater detail.

\section{Context}

The findings from separate research which identified the explanatory circumstances (or influencing factors) in CSR stakeholder management (O'Riordan 2010, p. 355) suggest that 'context' remains a key element in the new conceptualisation. This element reflects how managers, as one stakeholder group within the company, ${ }^{3}$ are required to address both their own interests as well as those of other

\footnotetext{
${ }^{3}$ Here the term 'company' is defined to embrace stakeholder groups including shareholders i.e. the owners and/or the employees of the company but not their families who are understood to belong to the stakeholder group: society/community.
} 
stakeholder groups (such as customers, society, suppliers, the government, etc. as depicted in the illustration) when formulating their strategic plans. In short, consideration of the context element as a first step in CSR management enables the integration of an inclusive stakeholder perspective into strategic business planning by facilitating decision-makers to initially establish how their business decisions impact collective value creation for all interest groups throughout the entire value chain.

To elaborate, the context element of the framework highlights that the CSR management response may vary by geographic location or industry, and that it may change over time. Specifically in this regard, certain consulting approaches (e.g. CSR Asia 2013) propose particularly useful techniques for companies to identify their stakeholders which facilitate stakeholder engagement via interest group needs analysis. This practical management approach focuses on recognising innovative strategic interventions as well as support programme management, monitoring and evaluation.

Figure 3 below helps to more explicitly explain the further related components of the context element in greater detail. It depicts how the evidence which was gathered suggests that when undertaking the internal management analysis which leads to business decisions and action, CSR decision-makers are influenced by, but may also influence, external factors. This implies a differentiation between the 'macro- and micro-context' within which the company operates. The macro-environment includes the complete societal (external) context in which the organisation resides. The micro-environment comprises the firm's closer operating environment such as the industry sector in which it undertakes its business activities (Carroll and Buchholtz 2009).

First, the macro-environment is presented as a set of external conditional factors which determine the "playing field' or setting in which (all) stakeholders operate. This is defined (similarly to the original conceptualisation) to include the PEST operating environment relevant to the specific business activity undertaken. However, the revised version now extends this element to include aspects which were previously classified under both the 'stakeholder' and 'event' elements (Buchholz and Carroll 2009, p. 7). As a result, the external environment in the new framework closely mirrors the context box in the original version. Accordingly, it continues to portray the political, economic, social, technological and legal environment. Nevertheless, this element now additionally includes media influence (Crane and Matten 2004, p. 12; O'Riordan and Fairbrass 2008) stakeholder pressure and lobbying (e.g. Roddick 2000 , p. 7), as well as competitor activity and industry structure (e.g. Porter 1985; Ferrell et al. 2010, p. 311). These aspects were previously categorised under the 'stakeholders' element in the original conceptualisation.
Many of these factors are influenced by stakeholder expectations which are inter-related with the contextual factors addressed above.

Significantly, this element signifies how the operating context within which pharmaceutical companies function is particularly sensitive and difficult to manage. Further, it highlights factors which specifically impose complicating issues on the pharmaceutical sector such as the nature of their business, certain aspects of research and development (including biochemical and gene technology), as well as the (conflicting) external social and economic issues of providing and financing (state of the art) healthcare access to those in need (e.g. ISO 2010, pp. 65-66). The global nature of their complex business operations means that these aspects are further complicated in politically, economically or socially 'unstable' operating environments (e.g. Deresky 2000; Daniels and Radebaugh 2001). Nevertheless, even in the more developed target countries under examination, the research reveals how healthcare budget cuts are significantly changing the nature of the stakeholder relationships and the expectations within those partnerships is also in transition. In this regard, the context element has now been expanded to include many factors which were previously categorised under the 'event' element in the original framework. Since the diverse nature of global operating environments was identified in the research evidence as important, this relevant aspect is further addressed separately in greater detail in Fig. 4 below in the 'Additional Elements' section.

Second, the new revised framework additionally improves on the original version by highlighting the salience of internal influencing determinants on CSR practice. In doing so, it now places more significant emphasis on internal conditional factors in the management of CSR stakeholder engagement. To elaborate, this includes aspects such as leadership and individual values which considerably affect company culture. Company culture is interpreted to be driven by internal values combined with (and influenced by) the leader's cognitive stance on CSR stakeholder engagement (e.g. Welford 1995, p. 114; Trevino and Nelson 1999; Trevino et al. 1999; Fürst and Wieland 2004; Obama 2007; Ferrell et al. 2010, pp. 233-282). The in-depth interview evidence suggests that this may impact employee motivation and interest. Accordingly, the leadership approach may ultimately determine CSR awareness (and accordingly overall approach) within the company (Kotter 1990; Gini 1997; Crane and Matten 2010, p. 223). More specifically, these values manifest themselves in vision and mission aspects of CSR management which affect the overall objectives and scope of the CSR management response (e.g. Crane and Matten 2010, p. 185). Further, the company profile, including its origin, size (e.g. number of employees, sales revenues and capital), ownership type, and level of success 


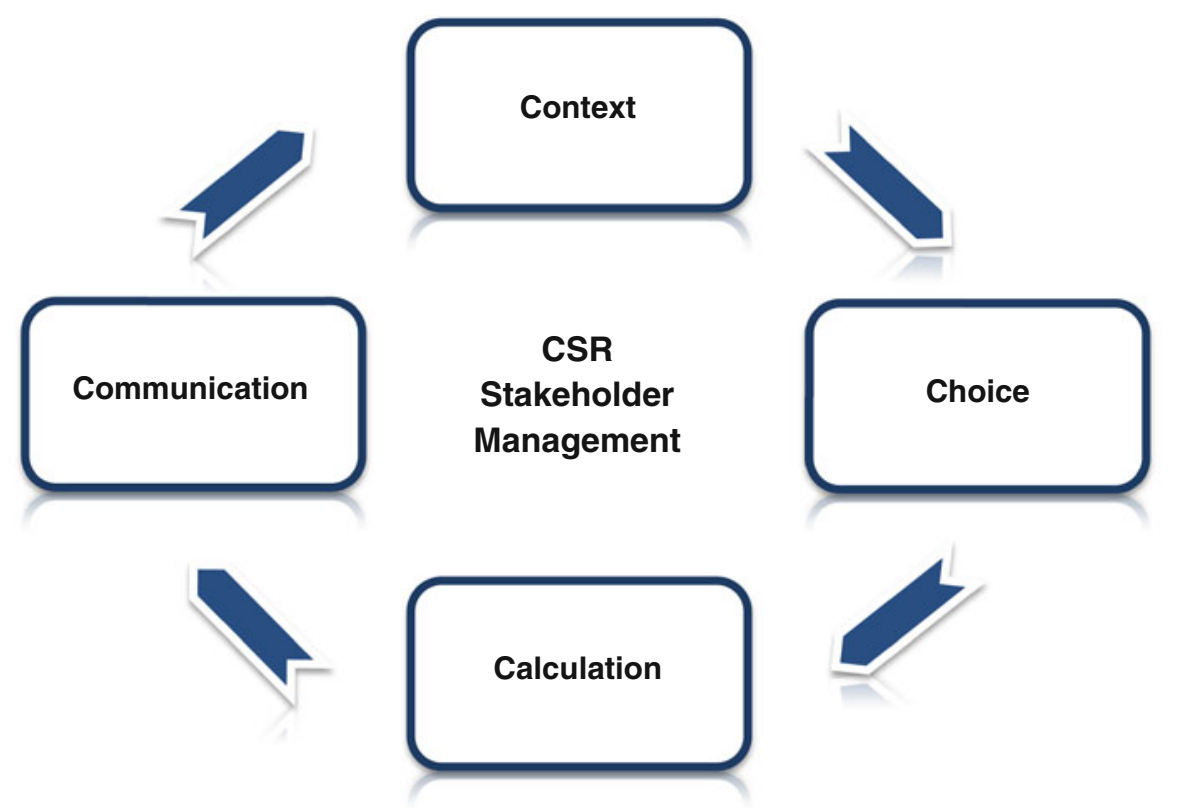

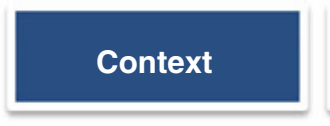
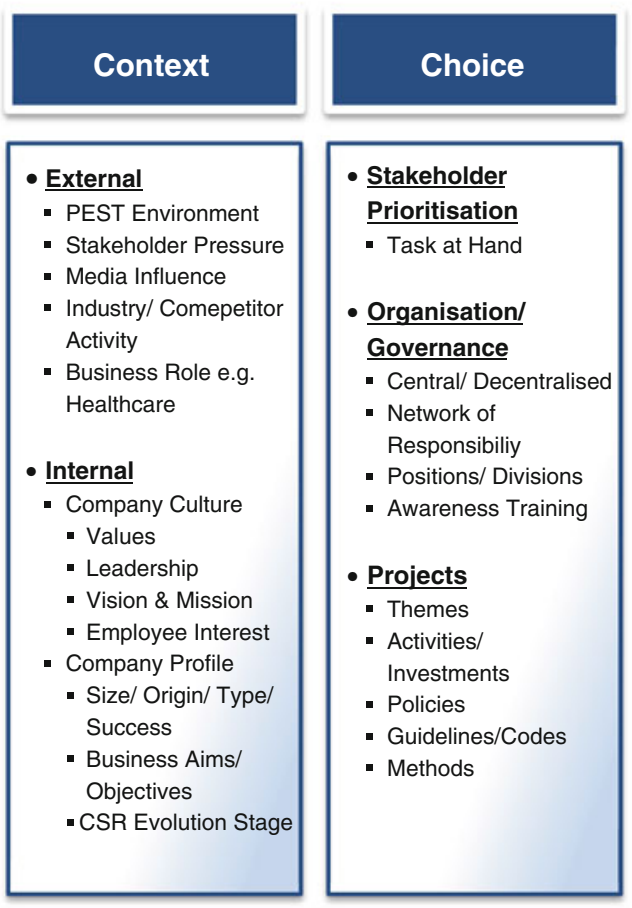

Fig. 3 Revised and refined framework in detail

(linked with not only size but also external listing status), affect both its CSR practice as well as stakeholders' expectations regarding its role in society (e.g. ISO 2010, p. 67). The company's CSR development (or evolutionary) stage is further identified as both an outcome and an influencing factor of the other internal (interactive) factors. Since this aspect was identified in in-depth interviews as

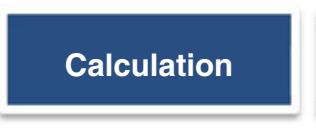

\section{Communication}

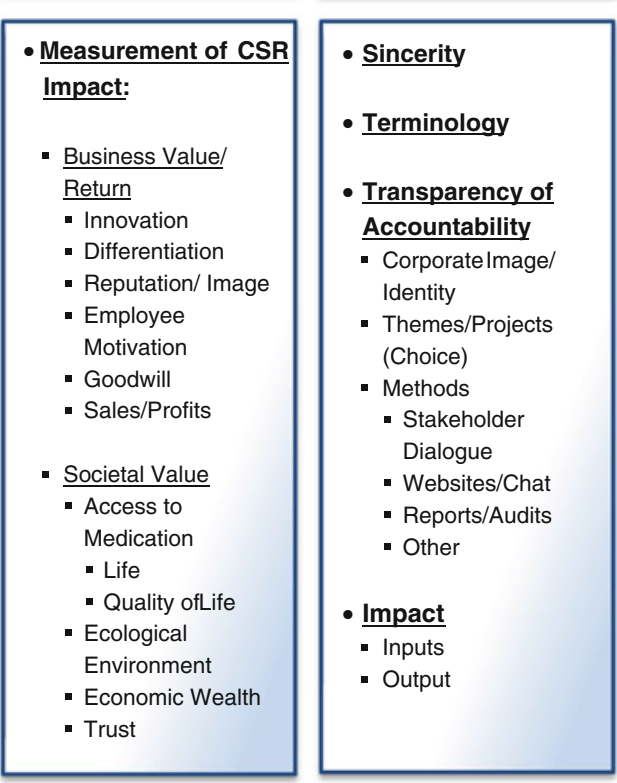

significant, it is addressed in greater detail in Fig. 5 below in the 'Additional Elements' section. For clarification, the specific insights presented here were derived from separate research (O'Riordan 2010, pp. 355-357).

Crucially, from a (internal) micro-perspective of the firm, the concepts proposed in stakeholder theory (Freeman 1984) suggest that investing time and other resources in 


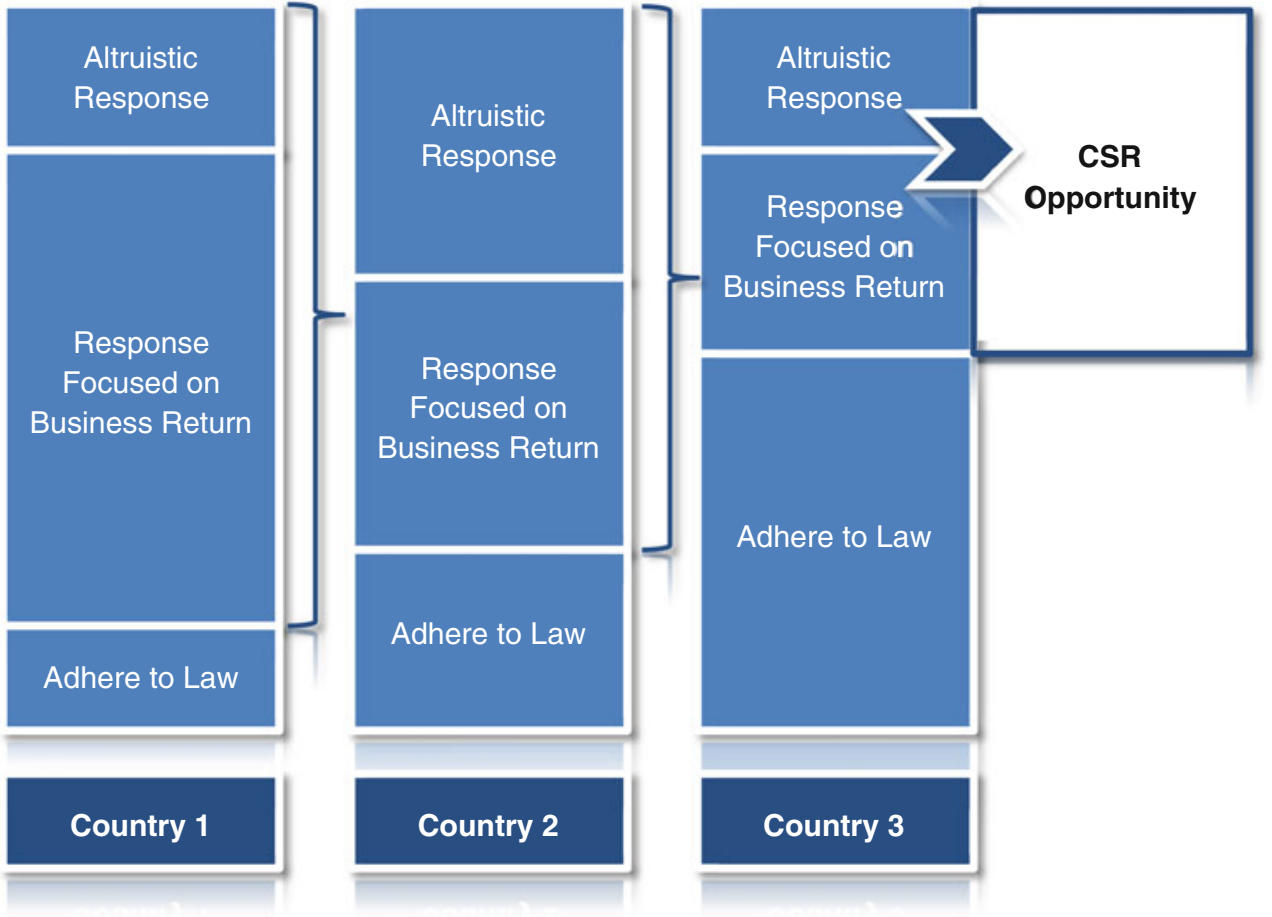

Fig. 4 Country variations-three classifications of CSR

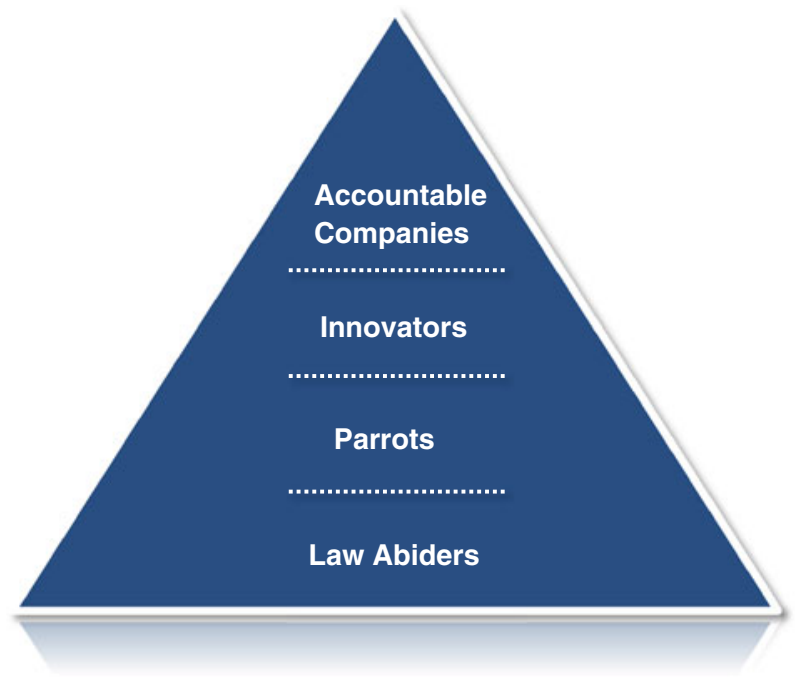

Fig. 5 Evolutionary stages of CSR company behaviour

addressing stakeholders' interests is a rational managerial activity. In this regard, the findings from separate research which inform the revised context element in Fig. 2 above highlights how decision-makers operating within the context of the pharmaceutical industry have come under increasing pressure from their stakeholders to act responsibly and to engage effectively with stakeholders via various engagement practices. Consequently, the fresh evidence which was presented above proposes how, in contrast to the explicitly profit-orientated focus typically held by businesses in the past which invariably provided the basis for strategic planning and management approaches (e.g. Crane and Matten 2004, p. 50; 2010), consideration of stakeholder engagement and stakeholder dialogue within the context element approach is a critical first step in sustainable CSR management for two key reasons. First, it enables the integration of an inclusive stakeholder perspective into strategic business planning. Second, it facilitates decision-makers to initially establish how their business decisions impact collective value creation for all interest groups throughout the entire value chain.

Nevertheless, the task of developing effective CSR stakeholder strategies for individual business managers in general, but in particular in the pharmaceutical business, an industry that is often termed 'sensitive', remains without doubt a major challenge (O'Riordan 2006, 2010; O'Riordan and Fairbrass 2006, 2012a, b). The key dilemma facing management is undoubtedly the tricky question of how to balance the often competing interests of their various stakeholder groups fairly. It is to this complex matter that the next section now turns in order to address the second element in the framework: namely: 'choice'.

\section{Choices}

Within the context (see above) of its external (macro-) and internal (micro-) circumstances (presented above), in 
which managers make 'choices' about how to balance their stakeholders' frequently varying and conflicting interests (e.g. Hill and Jones 2007, pp. 374-377), the previous section advocated that a business needs to define CSR for itself through engagement with its stakeholders. It proposed that precisely at this intersection between the stakeholders and the company (i.e. the 'white space' at the centre of Elkington's triple bottom-line concept), that CSR priorities are set. Significantly, it is in this 'space' that business opportunities for creating the greatest impact from the resources invested can be found. Consequently, a key feature of managing effective CSR is reliable, transparent, forward-thinking, inclusive stakeholder engagement. A useful approach for identifying the key relationship attributes/opportunities that are likely to determine stakeholders' salience is the power-dependency, legitimacy and urgency of claim relationship concepts proposed by Mitchell et al. (1997, p. 854). More specifically in this regard, the triple bottom-line concept proposed by Elkington (1999) builds on the visions put forward in the original Brundtland Report 'Our Common Future' (1987) which aimed to develop a sustainable society by '...inspiring and enabling people to organise themselves in new, innovative and often unconventional ways...' (Jonker 2012, p. 19). This approach views the business activity as synonymous with value creation which occurs (not only from an economic perspective as was arguably the dominant mind-set in the past), but at the 'white space' in the (balanced) junction of the three inclusive goals: namely the economy as well as society and the environment.

Just how these competing interests are balanced (i.e. the specific methodology involved in stakeholder prioritisation and the rankings) is addressed in greater detail later in this section based on the findings which emerged in the separate research undertaken which forms the basis for this paper. But first, because the ideas presented here are new, the concepts of sustainable relationships and equitable reciprocation proposed immediately above are now addressed in greater detail. Furthermore, one approach is put forward which could help to most optimally balance the two components 'sustainable relationships' and 'equitable reciprocation' particularly in cases where these might conflict.

More specifically, to effectively manage CSR, consideration of the impact of (internal) business decisions on (external) communities/society as well as the environment throughout the value chain ensures (in contrast to a shortterm philanthropic approach) that the resources which decision-makers invest in their business can bring longterm, sustainable benefits both to their company and to society. To offer guidance when making these decisions, the choice element depicted in Fig. 2 incorporates three specific aspects of CSR stakeholder engagement. These are derived from insights which were obtained in the findings relating to the codes 'stakeholders', 'organisation' and 'projects' in separate research (O'Riordan 2010, p. 358). Significantly, that study of current managerial perceptions indicated the need for improvement in the management 'mind-set' with respect to the way in which decisionmakers currently consider the equitable reciprocation (i.e. the overall impact) of their business investments. This approach builds on social exchange theory which views relationships as social entities within the context of a social structure (Granovetter 1985) in which firms are interdependent and rely on reciprocation (Blau 1964; Donaldson and O'Toole 2007, p. 29). Significantly, this perspective constitutes the basis for creating 'multiple value' (Jonker 2012) or 'shared value' (Porter and Kramer 2011). It proposes transforming the social order so that commerce and environmental restoration are synonymous in a system which is designed to increase the general well-being of humankind through service, creative invention and ethical philosophy (e.g. Hawken 1993). This form of social/relational exchange concentrates on the relationship and the interaction between the parties in that affiliation rather than on the transaction (e.g. Håkansson 1982; Ford 1990). This theory both accepts the self-interest motivation of the parties within the relationship and crucially recognises that in this exchange, the overall best interest is achieved when actors behave equitably and in the best interests of the partnership (e.g. Smith 1776; O'Riordan 2010, p. 353).

The revised framework presented in Fig. 2 suggests that if decision-makers were to follow a decision-making approach based on social/relational exchange theory, then better (i.e. more enduring) stakeholder relationships might be achieved. Crucially, this calls for new business solutions in which companies (via their decision-makers), who are arguably amongst the most powerful organisations in society, need to act as catalysts in re-designing a system in which commerce and production more positively impact living systems. Instead, of the current narrow focus on economic/financial tools for measuring business impact based on agency and transaction cost theories (e.g. Eisenhardt 1989; Donaldson and O'Toole 2007, pp. 21-36), such a transformation necessitates a fundamental move towards a restorative economy in which the power of business is harnessed to better distribute the wealth they create, generate growth and profits via more enduring (less destructive) methods which could more efficiently meet the world's exponentially increasing needs (e.g. Hawken 1993, p. 17). Significantly, this requires a considerable change from the traditional managerial mind-set which often forgets that our self-interest is inextricably linked with the interests of society.

To address the complex management task of balancing social and economic interests to achieve more sustainable 
relationships and equitable reciprocation for the optimal mutual benefit of both society and business, recent scholarship is currently emerging which suggests that our current economic ideas are no longer sustainable (Hart and Milstein 2007; Wagner 2009; Visser 2011). As a result, new ways of organising are emerging in which the scope and quality of alternative values (such as sustainability) is often central.

Crucially, a key recognition in this evolving awareness is the focus on balancing stakeholder interests with a view to generating a fairer distribution (more equitable reciprocation) of the economic wealth created by business. Significantly in this regard, a visionary new study which focuses on how business models create 'multiple value(s)' addresses organising in and between organisations to generate social and ecological value as well as economic value (Jonker 2012, p. 7). This study has yielded entrepreneurially creative new discoveries on ways of managing which focus on balancing different values such as nature, care, attention and money (instead of just concentrating on economic variables measured by money as in the past). The three common denominators for this new approach in the search for a fairer way to balance multiple stakeholder interests which initially emerge as important are the aspects of: sharing, trading and creating. The mutual features of the aspects identified are

...working to create an experience/and or a community in relation to a product and/or service. Another central fundamental is cooperative collaboration (Jonker 2012:7).

Crucially, it is on the point of interface between social, environmental and economic factors at which all sorts of new business opportunities arise (see the 'Additional Elements' section below and Fig. 4 for further details). Significantly, such forms of collaboration are enabled both by entrepreneurship and the directly related task of implementing these new concepts across the entire value chain. The interim results from this new research initially suggest that the ability to connect with and interlink these phenomena is the route to long-term sustainable value creation (i.e. multiple shared value). This is where '...renewal, innovation and new business models come into existence' (Jonker 2012, p. 7). In short, this fresh evidence sheds light on new ways in which a forward-thinking, inclusive understanding of the impact of business decisions on communities throughout the value chain can bring long-term, sustainable benefits both their company and to society.

A particularly thought-provoking feature of balancing social and economic interests to achieve more sustainable relationships and equitable reciprocation that benefits both society and business more fruitfully is that money is no longer the only means of trade. Economic traffic, based on the new business model concept, is instead based more specifically on 'exchanging and satisfying needs'.

This means that having access to the means of production becomes more important than owning them (Jonker 2012:7).

In this new approach 'using' becomes more salient than 'controlling' the key factors/sources of 'production'. Significantly, however, such an economy can only be organised following a co-operative approach based on the longterm commitment of the parties involved.

This makes securing trust in relations and in collaboration a necessary condition (Jonker 2012:8).

Critically, in this respect, the research in this field is still developing and further exploration is required to discover new streams, categories, features and values of the type of new business model discussed above in order to more clearly show how conventional practice can be replaced by more sustainable relationships that ensure greater equitable reciprocation to optimise the future mutual impact of economic entrepreneurship for both society and business.

Having explained the concepts of sustainable relationships and equitable reciprocation which proposes a new and quite visionary approach for more optimally addressing how to balance competing stakeholder interests, this section now addresses the specific method involved in making 'choices' about stakeholder prioritisation within the context of a pharmaceutical industry setting, as well as the rankings revealed in the separate research that was undertaken which forms the basis for this paper.

In this regard, Fig. 3 above helps to explain in greater detail three further related components of the choice element. To elaborate, the 'choice' element partly replaces two of the elements in the 'CSR strategy development' phase of the original conceptualisation (namely 'alternatives' and 'strategy'). In doing so, it portrays how (within their operating context) CSR decision-makers are required to take decisions concerning three particularly salient aspects of CSR practice. These include options regarding stakeholder prioritisation, organisation and projects/activities.

More specifically, based on the findings obtained from separate research, the stakeholder identification and prioritisation process is updated to now focus on the importance of the project-specific task at hand when identifying which stakeholders are most salient (e.g. Clarkson 1999; Frooman 1999; Greenwood 2007; Laplume et al. 2008, p. 1161; Crane and Matten 2010, p. 62; CRS Asia 2013). Within the context (see above) of the key relationship attributes between a business and society discussed above, managers make choices about how to balance their stakeholders' frequently varying and conflicting interests (e.g. Hill and Jones 2007, pp. 374-377). In doing so, based on 
the mind-set outlined immediately above, stakeholders' salience (i.e. power-dependency, legitimacy and urgency of claim relationship) as proposed by Mitchell et al. (1997, p. 854) is determined and stakeholders are identified.

The fresh evidence which was obtained to examine the specific stakeholder prioritisation choices of the pharmaceutical decision-makers in the target sample suggest that although the process is evolving, respondents in both counties identify and rank customers, employees, and their own internal directors as their most important stakeholders by far. This finding confirms previous literature regarding ranking in general (e.g. Burchell and Cook 2006). Not surprisingly for this industry, doctors and patients are additionally strongly emphasised by interviewees as important stakeholder groups (Company 1 2008; Company 11 2008; Company 15 2008; Company 17 2008). Some respondents explicitly state that 'shareholders' are seen as a key stakeholder group (Company 1 2008; Company 4 2008; Company 7 2008; Company 16 2008). Additionally, others specifically mention the media or press as salient stakeholders (Company 1 2008; Company 4 2008; Company 13 2008; Company 16 2008; Company 18 2008). Interestingly, for this industry, trade unions, however, get the lowest rank in both countries in contrast with claims made in other scholarship (e.g. Crane and Matten 2007). Significantly, however, other stakeholder groups such as 'future generations', 'excluded potential patients in developing countries', or (more controversially) those who may potentially be affected by products and procedures such as use of stem cells or cloning are not mentioned. This may be due to the fact that these complex issues are deemed 'tricky' to communicate, and/or that (possibly due to the complexity involved) the decision-makers in this industry have (for whatever reason(s)) not yet developed a satisfactory CSR stakeholder response on these matters. As a result, the stakeholder group 'other' has been developed to address this aspect and the other groups mentioned in detail here which, due to their number, could not be adequately depicted in the illustration.

Figure 3 further illustrates how CSR decision-makers additionally take organisation decisions regarding how to arrange, structure and position their CSR activities within their other business operations. This aspect includes activities such as opting for a centralised or decentralised approach (e.g. Trompenaars and Hampden-Turner 2004, p. 3), selecting positions and divisions, or electing members for CSR projects from a network of other responsible functions. Additionally, it essentially requires training to communicate CSR awareness among (all) employees (e.g. Greenwood 2007; Crane and Matten 2010, pp. 130, 299). The new updated framework further suggests that CSR decision-makers specifically select CSR projects based on a prior cognitive stance regarding whether they prefer to ultimately follow a philanthropic approach or one that is integrated into their business model in a more sustainable way (Kotler and Lee 2005; Crane and Matten 2010, p. 468). This cognitive stance is the outcome of the new mind-set discussed above under the context element. Depending on which approach is followed, CSR decision-makers decide on how to invest company resources on various options comprising themes, activities and other ventures, policies, and codes to guide their decisions (e.g. Crane and Matten 2010, p. 185). These choices additionally comprise the methods chosen to deliver that practice e.g. cash or product donations, knowledge or other assets (e.g. Kotler and Lee 2005). For clarification, these insights were derived from separate research which indicated that these factors were salient in CSR management (O'Riordan 2010, pp. 257-259).

Crucially, these choices are made in view of the critical issue that a business must first generate the value or wealth that it seeks to re-distribute to society/the community. As a result, the prerequisite for acting responsibly is first ensuring that the company reliably/sustainably generates business value/return to enable it to the desired create societal value. It is to this topic that the next section now turns.

\section{Calculation}

The previous sections highlighted how decision-makers currently focus narrowly on economic/financial tools for measuring business impact based on agency and transaction cost theories (e.g. Eisenhardt 1989; Donaldson and O'Toole 2007, pp. 21-36). This triggers the need for a considerable change from this traditional managerial mindset which often forgets that individual self-interest is inextricably linked with the interests of society. Nevertheless, precisely because economic results play a key role in the relationship between business and society, the new framework focuses pragmatically on the need for CSR managers to 'calculate' the expected outcome of their CSR stakeholder engagement activities (O'Riordan 2010, p. 362). Accordingly, this element has been upgraded from its position in the original framework as part of the 'implementation' phase of the CSR management response under the old heading 'output'.

Crucially, this calculation adopts the triple bottom line perspective (previously addressed in the 'Choices' section above) as a prerequisite for generating sustainable business development (e.g. Elkington 1999). This triple bottom-line perspective specifically means that to effectively manage CSR, decision-makers first need to understand that in contrast to a short-term philanthropic approach, the resources which they invest in their business can bring long-term, sustainable benefits for both their company and 
to society while minimising the harm done to the environment. A key prerequisite of this new approach requires a forward-thinking, inclusive understanding of the impact of business decisions on society and the environment throughout the value chain. Crucially, this focuses on the synergies which can be achieved from business activities which most optimally benefit (impact) both the business and society (e.g. Porter and Kramer 2006, 2011; Jonker 2012). Within this approach, a company's economic success realistically features as a significant aspect of responsible behaviour. This approach rationally presumes that profits first have to be generated before they can be distributed. Ultimately, in order to demonstrate the credibility which is increasingly demanded of them by society (e.g. Bertelsmann Stiftung 2007; Greenwood and van Buren 2010), consideration of these elements may help companies to 'capture' a more comprehensive understanding of the impact of their core business activities in the environment in which they operate.

Figure 3 above develops more explicitly on these ideas to concretely demonstrate how responsible business practice can add (multiple or shared) value both in terms of benefits in the form of both business return and societal value. In this regard, while the term 'calculation' may appear controversial to those who favour an altruistic, benevolent or humane approach to CSR, this element is deemed a realistic, frank and necessary aspect of CSR stakeholder management. This is particularly the case in business settings in which decision-makers find themselves responsible to external shareholders. Based on the rationale that the premise for a business to behave ethically is in the first instance its own long-term secured survival, economic performance and competitive advantage are proposed as critical factors which drive all business decisions (e.g. Smith 1776; Porter 1985). The focus here, however, is on showing how a CSR approach can provide the innovation and opportunity which leverages its practice to become a sustainable part of the self-interest of the company. Crucially, this perspective approaches the strategic management of stakeholder interests from a social/relational exchange theory stance (e.g. Blau 1964; Granovetter 1985; Donaldson and O'Toole 2007, p. 29) in line with the concepts presented in the 'Choices' section above. For clarification, this concentrates on the relationship and the interaction between the parties in that relationship (in line with the 'white space' activities at the triple bottom-line intersection as explained in the 'Context' and 'Choices' section above in greater detail) rather than on the transaction (e.g. Håkansson 1982; Ford 1990). While aiming to achieve more equitable reciprocation via sustainable stakeholder relationships, this theory accepts the selfinterest motivation of the parties within the relationship. In doing so, it crucially recognises that overall best interest within the exchange is achieved when actors behave equitably and in the best interests of the partnership (e.g. Donaldson and O'Toole 2007, p. 29).

More specifically, the 'calculation' element is developed from the insights obtained under the 'Expectations' code in separate research. Figure 3 first highlights in greater detail how responsible business practice can add business valuel return (e.g. Porter and Kramer 2006, p. 5). This can include innovative differentiation, improved reputation, and possibly also employee motivation. Overall, this can generate goodwill or a licence to operate in society (e.g. Murray and Vogel 1997, p. 142; Crane and Matten 2010, p. 495). Ultimately, this should lead to an improvement in sales/ profits. Second, and most significantly, Fig. 3 additionally significantly demonstrates the synergic societal value of those business investments (e.g. Porter and Kramer 2006, p. 8). This implies that in specific pharmaceutical industry context when streamlined, business investment can generate optimal results in a competitive environment in terms of access to (life-saving) medication, improved healthcare, and quality of life. In addition, this return to society can take the form of an improved ecological environment as well as greater economic wealth. Ultimately, this should lead to an improvement in trust among stakeholder groups in society (O'Riordan 2010, pp. 260-261).

Significantly, a key prerequisite to obtaining such trust or credibility is the communication which flows back to stakeholders. This could be viewed as the first step in an on-going dialogue and, therefore, as a key aspect of the stakeholder engagement steps proposed in the context element above (e.g. CSR Asia 2013). Consequently, communication which serves as the vehicle to interface between business activities and societal interests (i.e. at the 'white space' point of intersection of the triple bottom-line goals) is an additional critical step for identifying sustainable management solutions in the CSR stakeholder engagement process.

\section{Communication}

Crucially, the new revised framework advocates that only after the three other aspects of CSR management ${ }^{4}$ have first been systematically and thoroughly examined, planned and implemented, should 'communication' of CSR activities be undertaken. These insights derive from evidence which

\footnotetext{
4 (i.e. first analysing the context, second making choices based on an enlightened mind-set on the innovative opportunities that exist for business in line with the new business model concept described in greater detail above, and third calculating the return via a collaborative relationship approach which aims to achieve the optimum outcome for the partnership as opposed to individual interests in that partnership).
} 
was obtained with respect to the codes 'terminology', 'stakeholders', 'communication', 'organisation' and 'projects' in separate research (O'Riordan 2010, p. 362).

To elaborate, Fig. 3 above illustrates in greater detail how the 'communication' element synthesizes the discussion presented previously which advocated that an essential part of any CSR announcement involves a clear understanding (by all stakeholders) of the company's essential economic responsibility alongside its social and environmental obligations (e.g. ISO 2010, pp. 73-76). More specifically, this premise of enhanced sincerity involves the employment of considered terminology (e.g. May et al. 2007) which more transparently communicates the company's accountability in society (Waddock 2002, p. 219). The contention is that this communicated pledge to assume responsibility for the impacts of their business practices could potentially serve to improve firm's credibility and win back stakeholder trust (e.g. Blau 1964). However, a prerequisite for this transformation is that their business practices are supported by a CSR management response process which includes a clear approach, policies and the decisions which stand behind those practices. In this regard, the communication element is not only clearly inter-related specifically with the 'choice' but also intrinsically with the other elements of the new framework. In this regard, the evidence suggests that the firm can improve its corporate image by explicitly identifying itself with the chosen themes and projects related to its specific competence. When communicating these chosen CSR activities, a range of methods may be selected including person to person stakeholder dialogue (Burchell and Cook 2006; Greenwood 2007), the use of websites and chat to interact with stakeholders (e.g. Burchell and Cook 2008, p. 35), and/or dissemination of more transparent information via reports and auditing (e.g. Gray et al. 1995; Crane and Matten 2010, p. 551).

Essentially, the new updated explanatory framework proposed in this paper presents a tool for achieving this CSR management 'response' process. In this new approach the empirical in-depth interview evidence revealed that communication of both inputs (e.g. CSR expenditure and other resources) and more significantly outputs (e.g. in a pharmaceutical industry context: alleviation of social need or illness, or improvement in the quality of life) are important. As a result, communication has been reclassified in this revised framework based on the evidence obtained in separate research which indicated its significance in CSR practice. Accordingly, the new framework elevates this element's importance to acknowledge its key role in CSR stakeholder engagement (e.g. ISO 2010, pp. 73-76). It has now been upgraded from its original position as part of the implementation phase of the CSR process in the first version and renamed to depict the concept of overall 'impact' to society (rather than just the limited output from management activities within the scope of the business value chain).

In short, the communication element emphasises the inherent salience of declaring sincere and meaningful CSR only after ethically enabled choices have first been genuinely evaluated and authentically implemented into the business operations along key areas of the value chain. These insights derive from the findings with respect to the codes 'stakeholders', 'communication', 'organisation' and 'projects' which were obtained from separate research (O’Riordan 2010, pp. 262-263).

In summary, to more explicitly demonstrate its practical value, Fig. 3 above demonstrates each of the four interlinked management components of the new revised framework in greater detail.

Similar to the original framework, the revised version is designed to be worked through in a series of separate but interlinked phases. This should help to enable business executives to methodically and systematically manage the entire CSR stakeholder engagement decision-making process in one comprehensive, all-inclusive and structured approach (O'Riordan and Fairbrass 2008; O'Riordan 2010, p. 354). Empowered by a new culture which actively seeks innovative new ways to create shared/multiple value for CSR decision-makers, the new framework could help to foster the transition towards a more inclusive society (new culture) in which wealth creation is shared more fairly across the various relevant interest groups. Significantly, because this noble goal is undoubtedly ambitious (and could actually be viewed as idealistic) it is certainly challenging to achieve in practice. Crucially, however, by recognising and including (via the vehicles of engagement and dialogue) the inherent interest groups as reciprocal partners, the proposed framework offers a practical solution. Consequently, the recommended steps in the framework help to enable the reciprocal balance of multiple shared benefits which thereby ensures that a broader range of interests are valued and respected.

\section{Additional Elements}

The 'context' element now incorporates some fresh insights which were identified in separate research as important to explain the explanatory circumstances which influence CSR behaviour such as how CSR management response may vary by geographic location or industry, and that it may change over time (O'Riordan 2010, pp. 364-375). Significantly in this regard, the findings from the research evidence highlights both how the firm defines and positions itself in its external environment, and second, the nature of company's internal CSR development (or evolutionary) stage. This section now examines these two subjects more closely (O'Riordan 2010, p. 364). 
First, to help decision-makers to more clearly define and position their CSR activities within the context of their external global operating environments, Fig. 4 above addresses the diverse nature of the global operating environments which exposes CSR decision-makers to key challenges when attempting to navigate through the complex contextual circumstances. When addressing the contextual determinants introduced in the 'context' element of the new updated explanatory framework (discussed above) as the proposed first step in establishing stakeholder engagement, the evidence suggests that the complexities involved in the pharmaceutical companies' external operating environment not only complicate, but also additionally cause both diversity and dynamism in CSR management response. In short, managers struggle with illdefined expectations on complex issues that question the very nature of the firm's relationship with society. In attempting to address these challenges and decide how to best respond to them, the interview findings expose the need to classify managerial conceptions of what specifically constitutes CSR, and what comprises 'basic' business practice as a key step which could help to improve the current lack of clarity indicated in previous general scholarship in this area (e.g. O'Dwyer 2003; O'Riordan 2010, p. 364).

To elaborate, the fresh empirical evidence presented in this work revealed that some stakeholders characterise CSR to exclusively comprise an altruistic, benevolent or humane approach. Others take a wider view which may include (varying types or degrees of) business activities. Arguably each one is valid. However, in order to be clear about their business relationship with their stakeholders in society, decision-makers need to precisely consider what business practices 'count' as CSR. Such a definition serves to ensure the effective management of all (including internal employee) stakeholder expectations. In addition, this step is a key prerequisite for (and, therefore, interrelated with) the 'calculation' component of the revised explanatory framework. This triggers the need for a practical illustration to help decision-makers to establish precisely how CSR activities are currently defined and positioned in order to identify the business opportunities inherent in responsible practice. Figure 4 is included in response to research findings which revealed how national differences generate challenges which may complicate CSR stakeholder management at the local or regional operating level.

To address this issue, Fig. 4 above divides business behaviour into three categories: namely a base-line definition of responsible behaviour which 'adheres to the law'; a category that relates to all additional voluntary responsible behaviour beyond the base-line legal requirement from which some type of concrete anticipated quantitative or qualitative benefit or 'return to the business' is expected; and finally, responsible behaviour of an 'altruistic' nature which does not presume any direct business reward. In doing so, Fig. 4 highlights the possible contrasting nature of the 'givens' or contextual circumstances in the various external operating environments in which companies operate which impact their CSR behaviour. As a result, this figure explains how the 'playing field' for embarking on CSR practices can vary from country to country depending on their given stage of development as well as their PEST and other external environment factors (see 'Context' above for further details). Most significantly, this figure suggests that these differences potentially offer CSR differentiation opportunities, which, when managed effectively, could present new effective routes to CSR stakeholder 'white space' engagement (O'Riordan 2010, pp. 364-370). For clarification, the country depictions are envisioned as examples of possible external operating conditions only. Accordingly, they are not intended to 'match up' with the number of countries studied. This is the reason why three countries are depicted in this figure when only two were included in the study.

In order to help decision-makers to appreciate the nature of their internal response 'readiness' to address the external opportunities depicted in Fig. 4 immediately above, Fig. 5 above more specifically examines the impact of internal factors on the management of stakeholders. By classifying CSR behaviour into four evolutionary stage of CSR management, this component was developed in response to findings which suggested a lack of alignment between the company's stated values/principles and its CSR operational policies and programmes/practices i.e. the 'rhetoric versus reality' debate which questions the authenticity of CSR practice among firms (O'Riordan 2010, pp. 370-375).

Figure 5 illustrates one interpretation of the complex range of management responses to CSR which the research findings exposed. To elaborate, it identifies a 'law abider' group which characterises those companies, which, rather than pretending to aspire to CSR in empty rhetoric, simply focus on fulfilling the base-line requirement of adhering to the laws and regulations posed upon them by their operating environment (as depicted in Fig. 4 above as level 1 CSR behaviour). Generally, companies within this category do not typically 'whitewash'. In actual fact, decisionmakers in this cluster may indeed misunderstand just how much CSR behaviour is actually being undertaken by the company in merely adhering to the law. Essentially, this group might benefit from a clearer understanding of what CSR means in order to inform itself, as well as its internal and external stakeholders, and thereby better leverage its unidentified responsible behaviour deeds.

The second set of companies, labelled here as 'parrots', are initially similar to the law abider group in that they 
(presumably) adhere to the base-line requirement of fulfilling the laws and regulations posed upon them by their operating environment (as depicted in Fig. 4 above). ${ }^{5}$ However, in contrast with the law abiders, this group has responded to social expectations on CSR behaviour with 'bolt on' practices. In other words, these are the 'window dressers'. As a result, although the amount of rhetoric about CSR increases, no fundamental change takes place within the company regarding its understanding of CSR, its opportunities or its 'meaningful' CSR practice. Employees within these companies are generally not aware of what CSR is, its role within the company, or who is responsible for undertaking it. Crucially, the type of response typified in this cluster most particularly generates a sceptical stance among internal and external stakeholders.

Companies classified in the third category labelled here as 'innovators' are those which fulfil the base-line requirement of adhering to the laws and regulations posed upon them by their operating environment (as depicted in Fig. 4 above). They also minimise the amount of parroting undertaken (depicted within the category 'response focused on business return' in Fig. 4 above). This is the group in which (some key members or maybe even most) senior level management has undergone a fundamental change in their attitude regarding the role that companies play in society. A clear difference between this group and the 'parrots' is that 'innovators' demonstrate greater substance (in the form of a long-term outcomes-orientated approach) to realise broader stakeholder impact via their business investments. 'Innovators' are first characterised by their realistic understanding of the limitations (as well as the opportunities) of CSR stakeholder engagement. This includes overt admission of the overall need to (first reliably) achieve sustained economic return to ensure the longterm survival of the business. This additionally involves a self-critical stance which, without resignation, admits past mistakes and appreciates the boundaries (but more importantly the opportunities) inherent in investing its resources in CSR activities. Most significantly, while realistically focused on long-term economic interests, 'innovators' are concurrently aware of the positive effect their resources can leverage within society. In this respect, they actively seek dialogue with key stakeholder groups to learn and strive to get to grips identify the optimal synergic impact they can achieve within their operating environment. A key

\footnotetext{
5 For clarification, rather than implying that that companies 'evolve' from one group to another in this illustration, the intention instead is to suggest that these type of responses to the CSR 'call' simply exist within firms. As a result, various subsidiaries or projects within the same company could actually 'co-exist' at different levels of evolutionary development. Here committed leadership is required to stimulate accountable practice.
}

difference between this group and 'accountable companies' (addressed immediately below) is that these intentions are beginning to manifest themselves in the 'innovator' cluster. They are developing to become clearly visible within the way the business is organised and in how the values are translated into concrete processes. For clarification, the best-in-class examples of companies observed within the context of this research fit into this third level category.

Companies classified in the fourth category, labelled here as 'accountable companies' are those which intrinsically practice all CSR behaviour definitions (depicted in Fig. 4 above) with a focus on the maximum economic, societal and environmental impact for CSR business investments. Most essentially, this group understands that demonstrable positive social impact is the most certain route to long-term sustainable business success. Significantly, this view goes against the flow of the conventional economic and market trends and the emotions of the time. This means that decision-makers at these types of companies are intellectually engaged in a holistic way to identify innovative ways to better allocate business resources to achieve outcomes which positively impact a broader range of stakeholder interests. They base their business objectives on improving the environment in which they operate (Grant 2006). Rather than following the isolated goal of generating profits or company growth, they are interested in seeking insights to understand their potential to impact their operating environment within the context of the full picture (see for example Welford 2008). This type of company seeks a fundamentally new and creative (sustainable) way of approaching how its business impacts its environment. In doing so, this group of decision-makers possess the insight to both identify the opportunities (see Fig. 4), as well as to design motivating purpose for their employees (see for example Heal 2005) and customers (see for example literature on relationship marketing such as Donaldson and O'Toole 2007; Kotler et al. 2009, p. 18) into their CSR stakeholder engagement activities. Unfortunately, while many examples of responsible management were noted during this research enquiry, and several examples of individuals were encountered who earnestly appear to be aiming for (and in some ways achieving) these types of goals, in the final judgement, none of the companies examined have yet evolved to this desired state of accountable company culture.

In short, by identifying four evolutionary stages of internal company CSR practice response, this framework helps to explain why it may be possible that various companies (and sometimes even affiliates within the same company) might manage and communicate their CSR responses differently. For clarification these insights were derived from data collected in separate research (O'Riordan 2010, pp. 370-375). 


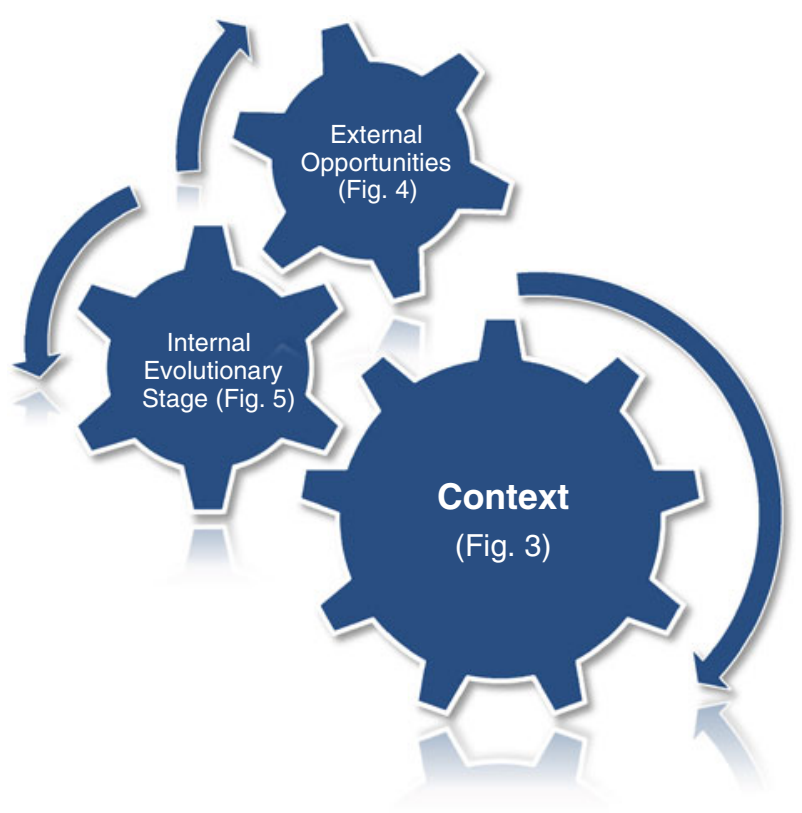

Fig. 6 The relationship between internal and external determining contextual factors

In summary, Figs. 4 and 5 above have proposed two new supplementary elements which are designed to provide additional guidance for CSR decision-makers by more explicitly depicting the conditional determinants of CSR practice within the context of both the firm's external and internal operating environment.

\section{The Interactions and Relationships Between the Components}

In light of the findings from separate research which advised developing the original framework version to more clearly signify the inter-relational linkages of its components (Company 3 2008; Company 15 2008), Fig. 6 below explicitly demonstrates how the external opportunities in the operating environment (Fig. 4) coupled with the internal stage of CSR development (Fig. 5) determine the company's response within its operating context (depicted in Fig. 3). Here the 'context' cog is larger in order to visually represent the key role it plays in CSR decisionmaking as described above in greater detail.

The fresh empirical evidence gathered and reported here establishes the foundations for the rationale for these components and their linkages (O'Riordan 2010, p. 377). Significantly, this expands on past scholarship which more generally suggested such possible linkages (e.g. Habisch and Jonker 2005; Crane and Matten 2007, p. 161).

This graphic illustration is designed to improve the framework's value as an instrument which maps CSR management processes when developing integrative management activities. By helping to explain the relationships between the concepts, this illustration demonstrates a work flow that aims to clarify the management steps that are required to generate synergic business and societal value (O’Riordan 2010, p. 342).

\section{The Framework in Practice: Pharmaceutical Industry Case Study}

Undoubtedly, for any business organisation, in contrast with legal matters which are settled in the courts, the less tangible and more interpretive aspect of how its CSR behaviour is viewed and evaluated by stakeholders (in other words in the 'court' of 'public opinion') is likely to continue to have a major impact on its interactions with them. Significantly, this interdependency ultimately affects the acceptance or legitimacy (see for example Lindblom 1994; Gray et al. 1995, p. 52; Mitchell et al. 1997, p. 863; Greenwood 2007, p. 321) the business ultimately wins from its stakeholders. Accordingly, stakeholder engagement/dialogue (see for example Greenwood 2007; Greenwood and Van Buren 2010) and discovering new ways to balance sustainable relationships and equitable reciprocation (especially in cases where these might conflict) will persist as a matter of significant managerial interest.

More specifically, the context of pharmaceutical firm's relationships and communications with their stakeholders (see for example Burchell and Cook 2006, 2008) is especially important because the aspects inherent in their operating environment (including the nature of their business in the sensitive area of healthcare, the fact that their business activities are often undertaken in developing, third world, or other disaster, or poverty-stricken locations, the issue that those in need of their therapeutic products and services often derive from vulnerable groups of society e.g. the ill, the elderly, children or mothers) clearly all affect stakeholder expectations, and consequently reaction. As a result, the pharmaceutical industry in particular has come under increasing pressure from its stakeholders to act more responsibly. Since the pharmaceutical business activity impacts a diverse range of stakeholder interests (including mutually inclusive groups such as shareholders, employees, [directors, managers and lower level staff], patients and their families/significant social groups [which may extend to society at large], doctors, healthcare institutions, insurance companies, government regulatory and financing authorities, the media, NGOs, insurance companies, suppliers, research institutions for example), which often conflict or even collide, the evidence presented suggests that these groups' expectations need to be recognised, and 
at least considered (although possibly not always fulfilled based on reasons explained earlier).

Essentially, this suggests why attempting to balance the resulting potential range of diverse (rational and irrational, evolving) expectations possible (which the above discussion indicated are additionally complicated by circumstantial conditions), within the spirit of the stakeholder engagement concept, poses a particularly complex task for pharmaceutical decision-makers for three specific reasons. First, insurance companies or governments (i.e. often not the patients themselves) are the customers of (life-saving/ enhancing) pharmaceutical products. This means the consumers of this industry's' products and services (i.e. patients) leverage less control in the 'buying decisionmaking process' (see for example Kotler et al. 2009). Second, the complicated nature of the products requires particular regulations regarding development, production, distribution and application which may be difficult for many non-experts to sufficiently comprehend. Clearly this lack of comprehension can affect stakeholder ((mis)understanding) and accordingly expectations'. Third, the academic literature states that stakeholders (including not only management decision-makers themselves, but also the media, and various other lobby groups) do not always behave rationally (e.g. Greenfield 2004), or fairly (e.g. Wagner 2006). This claim is supported by empirical evidence gathered in indepth interviews which indicates that the operating environment in which pharmaceutical decision-makers take business decisions is complicated by the nature of health issues (O'Riordan 2010, pp. 237-239). Part of this issue could be interpreted to lie in the fact that many of the factors driving their behaviour are based on perceptions which are dependent on personal interests which view healthcare as a basic human right.

Crucially, while the revised conceptualisation arguably improves on the original prototype by authenticating it via the empirical research undertaken with selected senior business managers in this field, a significant consideration with respect to all of the concepts and relationships within the framework proposed in this paper is that they are still very much evolving and provisional. As a result, the framework requires further validation. Furthermore, the search for the 'right recipe' for the complex task of managing sustainable CSR is about proposing an approach rather than providing a concrete step-by-step method, process or set of rules. Instead, it is about a frame of mind, a direction, a route, perhaps even a philosophy, but not a formula of proven prescriptions for success. Consequently, at best this work can contribute by offering basic guidelines and tools as a first step to 'help' business decision-makers to 'see' potential business opportunities via a responsible management approach to strategic planning and policy implementation activities.
Critically, a fundamental principle of the approach proposed in this paper is that CSR is not interpreted as a moral matter but rather as a systematic set of steps which are designed to guide business decision-makers when addressing the hard practicalities of management (such as reputation, supply chain, human resources, marketing and other key business functions). In other words, while the paper is prescriptive in nature (and accordingly normative because it advocates a set of practical guidelines based on responsible values), a significant determining factor in this approach is that these steps are recommendations which can be empirically tested (Küpper 2011, pp. 140-144). This moves the proposed concept out of the realm of subjective values or beliefs and into the scientific empirical or value neutral domain (e.g. Weber 1917, 1988). In this approach, the most optimal outcomes for both business and society are identified and empirically validated (e.g. Homann and Lütge 2005). More specifically, these results could be empirically tested in subsequent research. For instance, to address the dilemma of satisfactorily balancing stakeholder interests, causal links could be established on degrees of win-win in the interplay between private and public interests (such as occur in 'tragedy of the commons' issues Hardin 1994). This could be addressed by measuring data outcomes (either historically or predicted) to identify those business solution outcomes which most favourably align private with public interests (as indicated in an approach suggested by Pies et al. 2009, p. 380 cited in Küpper 2011, p. 142). Significantly, this approach, which elevates the study of CSR management into the scientific realm, indicates a key starting point for further research on this subject.

\section{Conclusions}

This paper highlights a gap in the current scholarship concerning the essential elements and steps involved in managing CSR, particularly from a practitioner perspective and in relation to an under-researched 'test case' industry such as pharmaceuticals. To address the lacunae identified, the paper offers a revised framework which is designed as a practical tool to guide managers in the UK and German pharmaceutical industry when responding to CSR challenges.

To achieve this aim, the paper presents rich, robust and triangulated empirical evidence obtained in separate research (O'Riordan 2010) which is employed to examine, test and improve an original version of an explanatory framework (O'Riordan and Fairbrass 2008). In furnishing important descriptive data with respect to how decisionmakers in the pharmaceutical industry in the UK and Germany interpret and practice CSR, those findings have crucially confirmed the need to conceptualise CSR and, 
most importantly, identified where alteration is required to the existing conceptualisation (O'Riordan 2006).

More specifically, the new conceptualisation employs data obtained in 2010 (O'Riordan 2010) to propose a prescriptive, comprehensive, systematic, integrated and long-term approach to stakeholder engagement which focuses on improving business credibility in society (both to its internal and to its external interest groups). Accordingly, given the legitimacy crisis caused by the recent global financial turmoil, this work presents a timely contribution to the current debate concerning the interdependency between modern business and society within a capitalist system (Welford 1995, p. 114; Fürst and Wieland 2004; Wagner 2006; May et al. 2007; O'Riordan 2010, p. 3; Porter and Kramer 2011).

Most significantly, the revised framework is designed to provide specific and practical guidance to CSR decisionmakers in the pharmaceutical industry which could help them to more systematically respond to the challenge of balancing their triple bottom-line responsibilities to their stakeholders in society (e.g. Hahn 2009). When employed in tandem with other frameworks and guidelines (such as the new ISO 26000 guideline), the new conceptualisation could offer the target group a workable approach for putting CSR into practice. This could help to improve this industry's overall accountability by integrating their stakeholder network responsibilities (context) into the business choices and calculations they make to ultimately improve both the way they practice CSR as well as their communication of that engagement.

Overall, the research and the frameworks proposed in this paper contribute to both the academic literature and CSR management for the target group in three key ways. First, the research helps to fill significant gaps in an area which was previously under-investigated in the academic literature by providing fresh, rich and empirical data with respect to the CSR practices in this industry. Second, it enhances the academic literature by conducting a comparison of the CSR practices in two countries and confirms some of the differences that were alluded to in past scholarship. Third, and most importantly, by providing a clearer understanding of the key elements involved when responding to its stakeholders, the new conceptual framework assists in identifying a more optimal approach to effective CSR stakeholder engagement. Consequently, if used wisely, the revised prescriptive analytical tool for managing CSR proposed in this paper could potentially help to improve the effectiveness of CSR management in the pharmaceutical industry. Crucially, the paper and the conceptual frameworks that it proposes provide a holistic and forward-looking approach to stakeholder engagement that focuses on improving business credibility in society. Ultimately, it is designed to provide specific and practical guidance to CSR decision-makers in the pharmaceutical industry which could help them to better respond to the challenge of balancing their triple bottom-line responsibilities to their stakeholders in society.

Whilst the research undertaken which underpins this paper was limited to examining CSR stakeholder engagement activities from the perspective of internal pharmaceutical company agents only, it can be viewed as a starting point for new research which could expand the scope of this work in three potential ways. First, future research in this field could be broadened to embrace the opinions of further stakeholders to qualify the internal validity of this work. For example, new research could be developed to include surveys, focus groups or in-depth interviews with lower level company employees or external stakeholders such as the media, non-governmental organisations, sections of the general public, and other relevant groups. Second, additional work on different industries (e.g. extraction and/or chemical or retail) and/or countries could help to establish external validity. Third, because the linkages suggested in the new framework are new, all of the conceptualisations presented in this paper require further testing. As a result, subsequent research is required to investigate the practical application of this framework into CSR management practice. More specifically, future research is recommended both to examine how to implement these conceptualisations into everyday practice in an integrated approach across all the business functions in the corporate system, as well as how to scientifically identify those business solution outcomes which most favourably align private with public interests.

Crucially, however, the principal precondition for successfully implementing this framework is first a fundamental transformation of the current mental construct regarding the way business is perceived and designed as an organisation in society. Significantly, the prerequisite for the type of progress required is an improved management mind-set which, rather than narrowly focusing on discrepancies between the natural and commercial world, recognises instead the synergic, critically inherent link between business and society. From this arguably more enlightened perspective of conscious mindfulness, a new vision of commerce (i.e. one which is inherently sustainable and restorative but which employs many of the historically effective organisational and market mechanisms of free enterprise) becomes evident. This re-examination of what business is and what it could become (O'Riordan 2010, pp. 433-452) could consequently decisively serve as a catalyst to unleash the (arguably) more powerfully positive role which business could be playing to facilitate a more restorative economy. Within this broader context, the new conceptual framework is one instrument which is designed to facilitate this transformation process. 


\section{References}

Agle, B. R., Mitchell, R. K., \& Sonnenfeld, J. A. (1999). Who matters to CEOs? An investigation of stakeholder attributes and salience, corporate performance, and CEO values. Academy of Management Journal, 45(5), 507-525.

Albareda, L., Lozano, J. M., Tencati, A., Midttun, A., \& Perrini, F. (2008). The changing role of governments in corporate social responsibility: Drivers and responses. Business Ethics: A European Review, 17(4), 347-363.

Bertelsmann Stiftung. (2007). Retrieved April, 2007, from www. bertelsmann-stiftung.de.

Blau, P. M. (1964). Exchange and power in social life. New York: Wiley.

Buchholtz, A. K., \& Carroll, A. B. (2009) Business and society. 7th (international student) edn. Canada: South Western Cengage Learning.

Burchell, J., \& Cook, J. (2006). It's good to talk? Examining attitudes towards corporate social responsibility dialogue and engagement processes. Business Ethics: A European Review, 15(2), 154-170.

Burchell, J., \& Cook, J. (2008). Stakeholder dialogue and organisational learning: Changing relationships between companies and NGOs. Business Ethics: A European Review, 17(1), 35-36.

Carroll, A. B. (1979). A three-dimensional conceptual model of corporate performance. Academy of Management Review, 4(4), 497-505.

Carroll, A. B. (1999). Corporate Social Responsibility: The evolution of a definitional construct. Business and Society, 38(3), 268-295.

Carroll, A. B., \& Buchholtz, A. K. (2009). Business and society: Ethics and stakeholder management (7th ed.). Stamford, CT: Cengage Learning, Inc.

Clarkson, M. B. E. (1999). Principles of stakeholder management. The Clarkson Centre for Business Ethics University of Toronto, Canada. Cited in A. B. Carroll \& A. K. Buchholtz (2009) Business and society: Ethics and stakeholder management (7th ed., p. 111). Stamford, CT: Cengage Learning Inc.

Company 1. (2008). Evidence from qualitative interviews which has been rendered anonymous for confidentiality purposes. (Source O'Riordan 2010).

Company 3. (2008). Evidence from qualitative interviews which has been rendered anonymous for confidentiality purposes. (Source O'Riordan 2010).

Company 4. (2008). Evidence from qualitative interviews which has been rendered anonymous for confidentiality purposes. (Source O'Riordan 2010).

Company 5. (2008). Evidence from qualitative interviews which has been rendered anonymous for confidentiality purposes. (Source O'Riordan 2010).

Company 7. (2008). Evidence from qualitative interviews which has been rendered anonymous for confidentiality purposes. (Source O'Riordan 2010).

Company 8. (2008). Evidence from qualitative interviews which has been rendered anonymous for confidentiality purposes. (Source O'Riordan 2010).

Company 10. (2008). Evidence from qualitative interviews which has been rendered anonymous for confidentiality purposes. (Source O'Riordan 2010).

Company 11. (2008). Evidence from qualitative interviews which has been rendered anonymous for confidentiality purposes. (Source O'Riordan 2010).

Company 12. (2008). Evidence from qualitative interviews which has been rendered anonymous for confidentiality purposes. (Source O'Riordan 2010).

Company 13. (2008). Evidence from qualitative interviews which has been rendered anonymous for confidentiality purposes. (Source O’Riordan 2010).
Company 14. (2008). Evidence from qualitative interviews which has been rendered anonymous for confidentiality purposes. (Source O'Riordan 2010).

Company 15. (2008). Evidence from qualitative interviews which has been rendered anonymous for confidentiality purposes. (Source O'Riordan 2010).

Company 16. (2008). Evidence from qualitative interviews which has been rendered anonymous for confidentiality purposes. (Source O'Riordan 2010).

Company 17. (2008). Evidence from qualitative interviews which has been rendered anonymous for confidentiality purposes. (Source O'Riordan, 2010).

Company 18. (2008). Evidence from qualitative interviews which has been rendered anonymous for confidentiality purposes. (Source O'Riordan 2010).

Crane, A., \& Matten, D. (2004). Business ethics: A European perspective. Oxford: Oxford University Press.

Crane, A., \& Matten, D. (2007). Business ethics. Oxford: Oxford University Press.

Crane, A., \& Matten, D. (2010). Business ethics. Oxford: Oxford University Press.

CSR Asia. (2012, Week 47, 21 November 2012). Lessons in stakeholder engagement by Gabriel Chong (Vol. 8). Retrieved December, 2012, from www.csr-asia.com.

CSR Asia. (2013). Stakeholder engagement and community investment and development. Retrieved April, 2013, from http://www. csr-asia.com/service.php\#2.

CSR Europe. (2012). Proactive stakeholder engagement from the European Alliance for CSR. Retrieved December, 2012, from http://www.csreurope.org/pages/en/stakeholderengagement.html.

Daniels, J., \& Radebaugh, L. (2001). International business: Environments and operations (9th ed.). Upper Saddle River, NJ: Prentice Hall, Inc.

Deresky, H. (2000). International management: Managing across boarders and cultures (3rd ed.). Upper Saddle River, NJ: Prentice Hall, Inc.

Doh, J. P., \& Guay, T. R. (2006). Corporate social responsibility, public policy and NGO activism in Europe and the United States: An institutional-stakeholder perspective. Journal of Management Studies, 43(1), 47-73.

Donaldson, B., \& O'Toole, T. (2007). Strategic market relationships: From strategy to implementation (2nd ed.). Chichester: Wiley.

Eisenhardt, K. (1989). Agency theory: An assessment and review. Academy of Management Review, 14(1), 57-74.

Elkington, J. (1999). Cannibals with forks: The triple bottom line of 21 st century business. Oxford: Capstone.

Esteban, D. (2008). Strengthening corporate social responsibility in the pharmaceutical industry. Journal of Medical Marketing: Device, Diagnostic and Pharmaceutical Marketing, 8(1), 77-79.

Ethical Corp. (2009). If Roche sneezes the pharmaceutical industry catches a cold. Retrieved September, 2009, from www. ethicalcorp.com.

Ferrell, O. C., Fraedrick, J., \& Ferrell, L. (2010). Business ethics: Ethical decision-making and cases. Stamford, CT: Cengage Learning, Inc.

Fischer, A. (2009). Is there no prescription? Reputation in the pharmaceutical industry. In J. Klewes \& R. Wreschniok (Eds.), Reputation capital (pp. 347-359). Berlin: Springer.

Ford, D. (Ed.). (1990). Understanding business markets-Interaction, relationships and networks. London: Academic Press.

Fraser, C., \& Zarkada-Fraser, A. (2003). Investigating the effectiveness of managers through an analysis of stakeholder perceptions. Journal of Management Development, 22(9), 762-783.

Freeman, R. E. (1984). Strategic management: A stakeholder approach. Marshfield, MA: Pitman Publishing, Inc. 
Freeman, R. E., Martin, K., \& Parmar, B. (2007). 'Stakeholder Capitalism' Journal of Business Ethics 74, 303-14. Berlin: Springer.

Friedman, M. (1970, September 13) The social responsibility of business is to increase its profits. The New York Times Magazine. New York: The New York Times Company.

Frooman, J. (1999). Stakeholder influence strategies. Academy of Management Review, 24, 191-205.

Fürst, M., \& Wieland, J. (2004). 'WerteManagementSysteme in der Praxis: Erfahrungen und Ausblicke' pp. 349-391. Handbuch Werte Management. Hamburg: Murmann Verlag GmbH.

Garriga, E., \& Melé, D. (2004). Corporate social responsibility theories: Mapping the territory. Journal of Business Ethics, 53, 51-71.

Gini, A. (1997). Moral leadership: An overview. Journal of Business Ethics, 16(3), 323-330.

Granovetter, M. (1985). Economic action and social structure: The problem of embeddedness. American Journal of Psychology, 91(3), 481-510.

Grant, R. M. (2006). Contemporary strategy analysis. Carlton: Blackwell Publishing.

Gray, R. H., Kouhy, R., \& Lavers, S. (1995). Corporate Social and Environmental Reporting: A review of the literature and a longitudinal study of UK Disclosure. Accounting, Auditing, and Accountability Journal, 8(2), 47-77. University Press.

Greenfield, W. M. (2004, January-February). In the name of corporate social responsibility. Business Horizons, 47/1, 19-28.

Greenwood, M. (2007). Stakeholder engagement beyond the myth of corporate responsibility. Journal of Business Ethics, 74, 315-327.

Greenwood, M., \& van Buren, H. J. (2010). Trust and stakeholder theory: Trustworthiness in the organisation-stakeholder relationship. Journal of Business Ethics, 95, 425-438.

Habisch, A., \& Jonker, J. (2005). Corporate social responsibility. Berlin: Springer.

Hahn, R. (2009). The ethical rational of business for the poorIntegrating the concepts bottom of the pyramid sustainable development and corporate citizenship. Journal of Business Ethics, 84, 313-324.

Håkansson, H. (Ed.). (1982). International marketing and purchasing of industrial goods: An interaction approach. Chichester: Wiley.

Hardin, G. (1994). The tragedy of the unmanaged commons. Trends in Ecology and Evolution, 9(5), 199.

Hart, S. L., \& Milstein, M. N. (2007). In search of sustainable enterprise. Value News Network. Retrieved from www. policyinnovations.org.

Hawken, P. (1993). The ecology of commerce: A declaration of sustainability. New York: Collins Business.

Heal, G. (2005). Corporate social responsibility: An economic and financial framework. The Geneva Papers, 30, 387-409. Columbia Business School.

Hill, C. W. L., \& Jones, G. R. (2007). Strategic management an integrated approach (7th ed.). Boston: Houghton Mifflin.

Hoffmann, C., \& Fieseler, C. (2010). Implementing stakeholder engagement: A case study from the pharmaceutical industry. In Paper published at the 10th Conference of the European Academy of Management, Rome.

Homann, K., \& Lütge, C. (2005). Einführung in die Wirtschaftsethik. Münster: Lit-Verlag.

IBLF. (2010a). Integrating CSR into mainstream business practice. International Business Leaders Forum. TPI Working Paper No. 2/2010 by Refal Serafin. Retrieved December, 2010, from www. thepartneringinitiatives.org.

IBLF. (2010b). Our approach: Leadership and collaboration. Retrieved December, 2010, from www.IBLF.org.

ISO. (2010). Guidance on social responsibility. International Standard ISO/DIS 26000. Geneva: International Organisation for Standardisation.
Jensen, M., \& Meckling, W. (1976). Theory of the firm: Managerial behaviour, agency costs and ownership structure. Journal of Financial Economics, 3(4), 305-360.

Jonker, J. (2012). New business models. Working Paper. Nijmegen: Nijmegen School of Management, Raboud University.

Jonker, J., \& De Witte, M. (2006). Conclusion: The real challenges of organising and implementing CSR. In J. Jonker \& M. De Witte (Eds.), The challenge of organising and implementing corporate social responsibility (pp. 237-247). Basingstoke: Palgrave Macmillan.

Kotler, P., Keller, K. L., Brady, M., Goodman, M., \& Hansen, T. (2009). Marketing management (12th ed.). London: Pearson/ Prentice Hall.

Kotler, P., \& Lee, N. (2005). Corporate social responsibility: Doing the most good for your company and your cause. Hoboken, NJ: Wiley.

Kotter, J. P. (1990) 'What leaders really do' Harvard Business Review 68 (May-June), 103-11.

Küpper, H. U. (2011) Unternehmensethik: Hintergründe, Konzepte und Anwendungsbereiche (2nd ed.). Stuttgart: Schäfer Poeschel.

Laplume, A. O., Sonpar, K., \& Litz, R. A. (2008). Stakeholder theory: Reviewing a theory that moves us. Journal of Management, 34(6), 1152-1189.

Lee, M. D. (2008). A review of the theories of corporate social responsibility: Its evolutionary path and the road ahead. International Journal of Management Reviews, 10, 53-73.

Lindblom, C. K. (1994). The implications of organisational legitimacy for corporate social performance and disclosure. In Paper presented at the Critical Perspectives on Accounting Conference, New York, NY

Lindgreen, A, \& Swaen, V. (2010). Corporate social responsibility. International Journal of Management Reviews, 12(1), 1-7 (Special Issue).

Lindgreen, A., Swaen, V., \& Johnston, W. J. (2009). Corporate social responsibility: An empirical investigation of U.S. organizations. Journal of Business Ethics, 85(Suppl. 2), 303-323.

Lozano, R. (2010). Proposing a corporate sustainability typology. Sustainability Research Institute (SRI) Paper. School of Earth and Environment, University of Leeds. ISNN 1753-1330.

Maak, T. (2007). Responsible leadership, stakeholder engagement, and the emergence of social capital. Journal of Business Ethics, 74, 329-343.

Maignan, I., \& Ferrell, O. C. (2000). Measuring Corporate Citizenship in two countries: The case of the United States and France. Journal of Business Ethics, 23, 283-297.

Mallen, B. (2012). Corporate social responsibility news and resources. Retrieved December, 2012, from http://www. mallenbaker.net/csr/CSRfiles/enron.html.

Maon, F., Lindgreen, A., \& Swaen, V. (2008). Thinking of the organization as a system: The role of managerial perceptions in developing a corporate social responsibility strategic agenda. Systems Research and Behavioral Science Special Issue: Systems Thinking and Corporate Social Responsibility, 25(3), 413426.

Matten, D., \& Moon, J. (2008). "Implicit" and "Explicit" CSR: A conceptual framework for a comparative understanding of corporate social responsibility. The Academy of Management Review, 33(2), 404-424.

May, S., Cheney, G., \& Roper, J. (2007). The debate over corporate responsibility. Oxford: Oxford University Press.

Miles, M. P., Munilla, L. S., \& Covin, J. G. (2002). The constant gardener revisited: The effect of social blackmail on the marketing concept, innovation, and entrepreneurship. Journal of Business Ethics, 41(3), 287-295.

Mitchell, R. K., Agle, B. R., \& Wood, D. J. (1997). Toward a theory of stakeholder identification and salience: Defining the principle 
of who and what really counts. Academy of Management Review, 22(4), 853-886.

Murray, K. B., \& Vogel, C. M. (1997). Using a hierarchy-of effects approach to gauge the effectiveness of corporate social responsibility to generate goodwill toward the firm: Financial versus non financial impacts. Journal of Business Research, 38, 141-159.

Noland, J., \& Phillips, R. (2010). Stakeholder engagement, discourse ethics and strategic management. A. Lindgreen \& V. Swaen (Guest Editors) International Journal of Management Reviews: Corporate social responsibility, 12(1), 39-49 (Special Issue).

O'Dwyer, B. (2003). Conceptions of corporate social responsibility: The nature of managerial capture. Accounting, Auditing, and Accountability Journal, 16(4), 523-557.

O'Riordan, L. (2006). CSR and stakeholder dialogue: Theory, concepts, and models for the pharmaceutical industry. MRES Dissertation, University of Bradford, Bradford.

O'Riordan, L. (2010). Perspectives on corporate social responsibility (CSR): Corporate approaches to stakeholder engagement in the pharmaceutical industry in the UK and Germany. $\mathrm{PhD}$ Thesis, Bradford University School of Management, Bradford.

O'Riordan, L., \& Fairbrass, J. (2006). CSR: Models and theories in stakeholder dialogue. In Paper presented at a Corporate Responsibility Research Conference, 4-5 September, 2006. Ireland: Trinity College Dublin.

O'Riordan, L., \& Fairbrass, J. (2008). CSR-Theories, models and concepts in stakeholder dialogue-A model for decision-makers in the pharmaceutical industry. Journal of Business Ethics, 83(4), 754-758.

O'Riordan, L., \& Fairbrass, J. (2012a). Managing CSR stakeholder engagement: A new conceptual framework. In Paper presented at the 11th World Congress of Congress of the International Federation of Scholarly Associations of Management (IFSAM), 26-29 June, 2012. Ireland: University of Limerick.

O'Riordan, L., \& Fairbrass, J. (2012b). Corporate approaches to CSR stakeholder engagement in the pharmaceutical industry. In Paper presented at the 11th World Congress of Congress of the International Federation of Scholarly Associations of Management (IFSAM), 26-29 June, 2012. Ireland: University of Limerick.

Obama, B. (2007). Dreams from my father. Edinburgh: Canongate Books Ltd.

OECD. (2001). Organisation for Economic Co-operation and Development (OECD) public policy and voluntary initiatives: What roles have governments played?. Working Papers on International Investment 2001/4. Brussels.

Peters, A., \& Roess, D. (2010). The role of governments in promoting corporate responsibility and private sector engagement in development. Gutersloh: UN Global Compact and Bertelsmann Stiftung.

Pfeffer, J., \& Salancik, G. (1978). The external control of organisations: A resource dependence perspective. New York: Harper and Row.

Phillips, R. (1997). Stakeholder theory and a model of fairness. Business Ethics Quarterly, 7(1), 51-66.

Phillips, R., Freemann, R. E., \& Wicks, A. C. (2003). What stakeholder theory is not. Business Ethics Quarterly, 13(4), 479-502.

Porter, M. E. (1985). Competitive advantage: Creating and sustaining superior performance. New York: Free Press Edition.

Porter, M. E., \& Kramer, M. (2006). Strategy and society: The link between competitive advantage and corporate social responsibility. Harvard Business Review, 84(12), 78-92.

Porter, M. E., \& Kramer, M. R. (2011). Creating shared value. Harvard Business Review, 89(1/2), 62-77.
Rifkin, J. (2005). Ultimate therapy. Harvard International Review, 27(1), 44-49, Cambridge.

Robson, C. (2004). Real world research (2nd ed.). Oxford: Blackwell Publishing.

Roddick, A. (2000). Business as unusual. London: Thorsons Publishers.

Schwartz, M. S., \& Carroll, A. B. (2008). Integrating and unifying competing and complementary frameworks: The search for a common core in the business and society field. Business and Society, 47(2), 148-186.

Secchi, D. (2007). Utilitarian, managerial and relational theories of corporate social responsibility. International Journal of Management Reviews, 9, 347-373.

Silberhorn, D., \& Warren, R. C. (2007). Defining corporate social responsibility: A view from big companies in Germany and the UK. European Business Review, 19(5), 352-372.

Smith, A. (1776). An inquiry into the nature and causes of the wealth of nations. Retrieved from www.adam.smith.org.

Spinello, R. A. (1992). Ethics, pricing and the pharmaceutical industry. Journal of Business Ethics, 11(8), 617-626.

Trevino, L. K., \& Nelson, K. A. (1999). Managing business ethics: Straight talk about how to do it right (2nd ed.). New York: Wiley.

Trevino, L. K., Weaver, G. R., Gibson, D. G., \& Toffler, B. L. (1999). Managing ethics and legal compliance: What works and what hurts'. California Management Review, 41(2), 131-151.

Trompenaars, F., \& Hampden-Turner, C. (2004). Riding the waves of culture: Understanding cultural diversity in business (3rd edn.). London: Nicholas Brealey Publishing.

UN Global Compact. (1999). United Nations Global Compact. Retrieved from www.unglobalcompact.org.

Visser, W. (2011). The age of responsibility: CSR 2.0 and the new DNA of business. London: Wiley.

Waddock, S. (2002). Leading corporate citizens. Boston: McGrawHill.

Wagner, G. R. (2006) Gesellschaftliche Verantwortung als Unternehmensbild? (Social responsibility as a company image). In $\mathrm{S}$. Hilger (Ed.), Kapital and moral. Cologne: Köln (Böhlau).

Wagner, M. (2009). Innovation and competitive advantages from the integration of strategic aspects with social and environmental Management in European firms. Business Strategy and the Environment, 18(5), 291-306.

WBCSD. (2002). The business case for sustainable development: Making a difference towards the Johannesburg Summit 2002 and beyond. Geneva: World Business Council for Sustainable Development.

Weber, M. (1917). Der Sinn der »Wertfreiheit« der soziologischen und ökonomischen Wissenschaften. In Collected papers on Wissenschaftslehre, Tübingen 1988 (first published in 1922, pp. 489-540).

Weber, M. (1988). Die 'Objektivität' sozialwissenschaftlicher und sozialpolitischer Erkenntnis. In Collected papers on Wissenschaftslehre. Tübingen: Johannes Winckelmann.

Welford, R. (1995). Environmental Strategy and Sustainable Development: The corporate challenge for the 21st century. London: Routledge.

Welford, R., et al. (2008). Reporting on community impacts-A survey conducted by the global reporting initiative. The University of Hong Kong, and CSR Asia. GRI Report.

Zinkhan, G. M., \& Balazsb, A. L. (2004). A stakeholder-integrated approach to health care management. Journal of Business Research, 57(9), 984-989. 